\title{
Casein Kinase 2 dependent phosphorylation of elF4B regulates BACE1 expression in Alzheimer's disease
}

\author{
Barbara Bettegazzi $\mathbb{D}^{1,2}$, Laura Sebastian Monasor ${ }^{3}$, Serena Bellani ${ }^{1,2}$, Franca Codazzi ${ }^{1,2}$, Lisa Michelle Restelli ${ }^{4}$, \\ Alessio Vittorio Colombo ${ }^{3}$, Nikolaus Deigendesch ${ }^{4}$, Stephan Frank (D) $^{4}$, Takashi Saito ${ }^{5,6}$, Takaomi C. Saido (D) ${ }^{5}$, Sven Lammich ${ }^{7}$, \\ Sabina Tahirovic ${ }^{3}$, Fabio Grohovaz ${ }^{1,2}$ and Daniele Zacchetti $^{2}$
}

(c) The Author(s) 2021

\begin{abstract}
Alzheimer's disease $(A D)$ is the most common age-related neurodegenerative disorder. Increased $A \beta$ production plays a fundamental role in the pathogenesis of the disease and BACE1, the protease that triggers the amyloidogenic processing of APP, is a key protein and a pharmacological target in AD. Changes in neuronal activity have been linked to BACE1 expression and A $\beta$ generation, but the underlying mechanisms are still unclear. We provide clear evidence for the role of Casein Kinase 2 in the control of activity-driven BACE1 expression in cultured primary neurons, organotypic brain slices, and murine AD models. More specifically, we demonstrate that neuronal activity promotes Casein Kinase 2 dependent phosphorylation of the translation initiation factor elF4B and this, in turn, controls BACE1 expression and APP processing. Finally, we show that elF4B expression and phosphorylation are increased in the brain of APPPS1 and APP-KI mice, as well as in AD patients. Overall, we provide a definition of a mechanism linking brain activity with amyloid production and deposition, opening new perspectives from the therapeutic standpoint.
\end{abstract}

Cell Death and Disease (2021)12:769; https://doi.org/10.1038/s41419-021-04062-3

\section{INTRODUCTION}

Alzheimer's disease (AD), the most common form of dementia, imposes a very high social burden, which has been steadily increasing in the last twenty years. The pathognomonic signs of $A D$ are the accumulation of the amyloid- $\beta$ peptide $(A \beta)$, with formation of fibrillar extracellular deposits ( $A \beta$ plaques) and the intracellular deposition of neurofibrillary tangles, composed by hyperphosphorylated protein tau. According to the amyloid hypothesis [1], extracellular $A \beta$ is the trigger of the pathogenetic process leading to neurodegeneration [2], even though intracellular $A \beta$ might also play a role [3]. The detrimental process started by $A \beta$ is further potentiated by other co-factors, such as Tau accumulation and inflammation [4, 5]. Despite insights provided by biochemical, genetic, and animal model studies, effective therapeutic interventions against $A D$ have not been devised and it is still debated which $A \beta$ species are neurotoxic and which are their cellular targets [6]. However, $A \beta$-directed therapeutics remain one of the most eagerly sought disease-modifying pharmacological strategies [7-9]. Particular attention has been devoted to BACE1, the enzyme that controls $A \beta$ production by cleaving the amyloid- $\beta$ precursor protein (APP), and whose dysregulation has been reported in $A D$ patients [10-13]. Despite the promising results of the first attempts of BACE1 inhibition $[11,13]$, recent studies have pointed out that there are many different BACE1 substrates involved in the regulation of the synaptic function [14], with possible detrimental effects as a consequence of prolonged BACE1 inhibition [15]. Recent data have also shown that the different APP cleavage products are able to influence brain network activity through their interaction with different neuronal receptors $[16,17]$. A precise definition of the link between synaptic activity and BACE1 modulation is still needed, even more so after the observation that $A D$ patients treated with BACE1 inhibitors showed a modest worsening of cognitive performance [18-20]. In this respect, the elucidation of the mechanisms controlling BACE1 expression may offer further insights into our understanding of the disease and in the development of therapeutic approaches.

BACE1 is expressed in neurons, especially at the presynaptic terminals $[21,22]$ and its activity increases with age in mouse, monkey, and non-demented human brain [23]. BACE1 elevation appears to correlate with amyloid pathology and accumulation of BACE1 is observed in normal and dystrophic presynaptic terminals surrounding the amyloid plaques in brains of $A D$ mouse models and patients [21, 22]. Interestingly, neurons around or in contact with amyloid plaques have been reported to show a hyperactive phenotype [24, 25], but evidence of a causative link between synaptic activity and $A \beta$ production is still scarce [26]. Unfortunately, the complexity of the regulation of BACE1 expression in neurons has made it difficult to fully understand mechanisms

\footnotetext{
${ }^{1}$ Vita-Salute San Raffaele University, via Olgettina 58, 20132 Milan, Italy. ${ }^{2}$ IRCCS San Raffaele Scientific Institute, via Olgettina 60, 20132 Milan, Italy. ${ }^{3}$ German Center for Neurodegenerative Diseases (DZNE) Munich, 81377 Munich, Germany. ${ }^{4}$ Basel University Hospital, Institute of Medical Genetics and Pathology, Schoenbeinstrasse 40, 4031 Basel $(\mathrm{CH})$, Switzerland. ${ }^{5}$ Laboratory for Proteolytic Neuroscience, RIKEN Center for Brain Science Institute, Wako, Saitama 351-0198, Japan. ${ }^{6}$ Department of Neurocognitive Science, Nagoya City University Graduate School of Medical Science, Nagoya, Aichi 467-8601, Japan. ${ }^{7}$ BMC - Biochemistry, Ludwig Maximilians University Munich, 81377 Munich, Germany. ${ }^{凶}$ email: bettegazzi.barbara@hsr.it; zacchetti.daniele@hsr.it

Edited by P.G. Mastroberardino
}

Received: 19 March 2021 Revised: 7 July 2021 Accepted: 12 July 2021

Published online: 04 August 2021 
responsible for $B A C E 1$ elevation in $A D$ and to clarify the relationship between $A \beta$ increase and BACE1 upregulation.

Both transcriptional regulation [27] and change in protein stability [28] have been described for BACE1. However, a translational control of its expression seems to be of direct relevance to $\operatorname{AD}[21,29]$. Reports have highlighted a role for translation initiation $[30,31]$, with the possible involvement of miRNAs [32-34] and general translation factors, such as elF2a [35]. This latter possibility, however, was questioned since genetic inhibition of elF2a phosphorylation was not able to revert the $A \beta$-dependent BACE1 increase or the amyloid pathology in transgenic AD mice [36]. BACE1 translation largely depends on the presence of its long, conserved, and highly structured transcript leader and is influenced by conditions of cellular stress [37]. Stress stimuli are known to modulate protein synthesis, mostly through the phosphorylation of translation initiation factors, including elF4B [38]. elF4B is part of the elF4 group of translation initiation factors, whose main function is to recruit the mRNA to the ribosome and to assist the scanning of the $43 \mathrm{~S}$ ribosomal initiation complex. elF4B has been proposed to favor the interaction of the mRNA with the initiation complex, by binding elF3 and the 18S rRNA, and to stimulate the eIF4A helicase in the unwinding of secondary structures in the transcript leader of mRNAs $[39,40]$.

We have recently reported that, in neurons, elF4B phosphorylation is tuned by the neuronal activity via the control of different kinase pathways. In particular, Casein kinase 2 (CK2)-dependent elF4B phosphorylation triggers elF4B localization at synaptic microdomains, increasing elF4B recruitment to the translation pre-initiation complex and favouring the translation of proteins endowed with highly structured transcript leaders [41]. In this work we demonstrate a causal relationship between neuronal activity, elF4B phosphorylation and BACE1 expression, and provide evidence for an elF4B-dependent increase in levels of $B A C E 1$ observed in neurons close to $A \beta$ plaques in murine $A D$ models and human brain tissue.

\section{RESULTS}

Involvement of elF4B in the regulation of BACE1 expression There is consensus that the presence of a highly structured and upstream AUG (uAUG) endowed 5'UTR determines an inhibition of BACE1 translation efficiency [30,42, 43]. However, there is still conflicting evidence about the relative contribution of uAUGs, secondary structures, or the coding sequence in the regulation of BACE1 translatability.

The effect of different 5'-UTR sequences (BACE1 native or BACE1 mutated in the 2nd uAUG) on the expression of either luciferase or BACE1 was investigated in both Hek293 cells and primary rat astrocytes (Fig. 1A-C, Fig. S1 A-C).

Panel B of Fig. 1 shows a significant inhibitory effect of BACE1 $5^{\prime}$ UTR on luciferase activity $(\sim 60 \%)$ in Hek293 cells and demonstrates that the effect is prevented by the mutation of the 2nd uAUG. The inhibitory effect of BACE1 5'UTR was even higher $(\sim 90 \%)$ in presence of the BACE1 coding sequence and, more notably, it was not influenced by the mutation of the 2nd uAUG (Fig.1C and Fig. S1C).

Based on these results, structural features of the $5^{\prime}$ UTR play a more relevant role than UAUGs in BACE1 translation. The elF4Adependent helicase activity of the translation initiation complex is crucial for the unwinding of secondary structures in the $5^{\prime}$ UTR of mRNAs. Accordingly, we investigated whether the helicase activity of elF4A could relieve $5^{\prime}$ UTR inhibition, focussing our attention on elF4B, a translation initiation factor that is known to be present in neurons and to stimulate elF4A [44, 45]. When elF4B was transfected in primary hippocampal neurons, its overexpression (Fig. 1D, H) was accompanied by a two-fold increase in BACE1, without changes in the levels of the alpha-secretase ADAM10, full-length APP, and other proteins (Fig. 1D-H). In this condition, we detected a slight increase in the soluble form of APP (Fig. 1D-I) that could be attributed to a higher BACE1 activity. Using antibodies able to specifically recognize the different soluble APP peptides, we observed that the levels of the soluble APP $\beta$ fragment were increased (Fig. 1D, J), with no change in the levels of soluble APPa (Fig. 1D, K). Interestingly, also A 342 levels were increased (Fig. 1L).

Conversely, when endogenous elF4B levels were reduced by transfecting hippocampal neurons for $96 \mathrm{~h}$ with a pool of siRNAs against elF4B, a reduction in the expression of BACE1 was observed (Fig. $1 \mathrm{M}-\mathrm{O}$ ), accompanied by a slight increase in the levels of the full-length APP (Fig. 1M, Q) and a reduction in the levels of its soluble fragment (Fig. 1M, R). Other proteins, such as AKT or ERK were not significantly affected (Fig. S2). Also in this case we observed that the decrease in SAPP total levels was accompanied by a reduction in soluble APP $\beta$ levels and $A \beta 42$ release, again with no change in the levels of soluble APPa (Fig. 1M, S-U).

\section{Neuronal activity increases BACE1 translation via elF4B}

Multiple BACE1 substrates are localized at the synapse and play an important role in synaptic function [46, 47], supporting the view that BACE1 might be controlled by neuronal activity [48]. Considering the impairment of neuronal connectivity observed in the early phase of AD pathology [49] and the ability of elF4B to modulate protein synthesis as a function of synaptic activity [41], we investigated whether neuronal activity promotes BACE1 translation via elF4B.

Treatment of the hippocampal neurons with $10 \mu \mathrm{M}$ bicuculline (Bic), an antagonist of the $\mathrm{GABA}_{\mathrm{A}}$ receptor, increased both excitatory and intracellular calcium activities, as evaluated by microelectrode arrays (Fig. 2A), as well as BACE1 levels (Fig. 2B, C). Increased neuronal activity promoted an increase in the levels of carboxyl-terminal fragments of APP (APP-CTF), measured under conditions of $\gamma$-secretase inhibition with DAPT (see the "Experimental procedure" section), with a concomitant slight reduction in the levels of full-length APP (Fig. 2B-E).

The increase in the levels of BACE1 was prevented by pretreatment with the pool of siRNAs against elF4B (Fig. 2F, G). The knockdown of elF4B (Fig. 2F-I, J-L) was also able to prevent the reduction in full-length APP levels promoted by bicuculline treatment (Fig. 2F, H) and the increase in APP-CTF levels (Fig. 2J, K).

Taken together, these results suggest a cascade of events in which synaptic activity promotes elF4B activation, with ensuing increase in BACE1 expression and APP processing, possibly up to $A \beta$ production.

Casein Kinase 2 mediates elF4B-induced BACE1 upregulation In a previous work, we demonstrated that Casein Kinases mediate the neuronal-specific phosphorylation of elF4B on the Ser504 residue and that this phosphorylation increases the recruitment of elF4B to the translation initiation complex [41]. Based on this evidence, we tested whether silencing or pharmacological inhibition of Casein Kinase 2 was able to interfere with the elF4B-induced BACE1 upregulation. As we predicted, knockdown of CK2 with specific siRNA for $96 \mathrm{~h}$ in primary hippocampal neurons prevented the activity-induced increase in elF4B Ser504 phosphorylation, without affecting total elF4B levels, as well as the increase in BACE1 expression induced by bicuculline treatment (Fig. 3A-E). As expected from their reciprocal regulation [50], CK2 downregulation produced a reduction of AKT phosphorylation on Ser473, leaving unaffected the levels of phosphorylated ERK (Fig. S3). Similarly, pharmacological inhibition of CK2 $(25 \mu \mathrm{M}$ TBB) or CK1 + CK2 $(10 \mu \mathrm{M}$ $\mathrm{D} 4476+25 \mu \mathrm{M}$ TBB), a condition that is even more effective in inhibiting elF4B phosphorylation (Fig. 3F-H), also prevented BACE1 upregulation upon Bic treatment (Fig. 3F, G). 

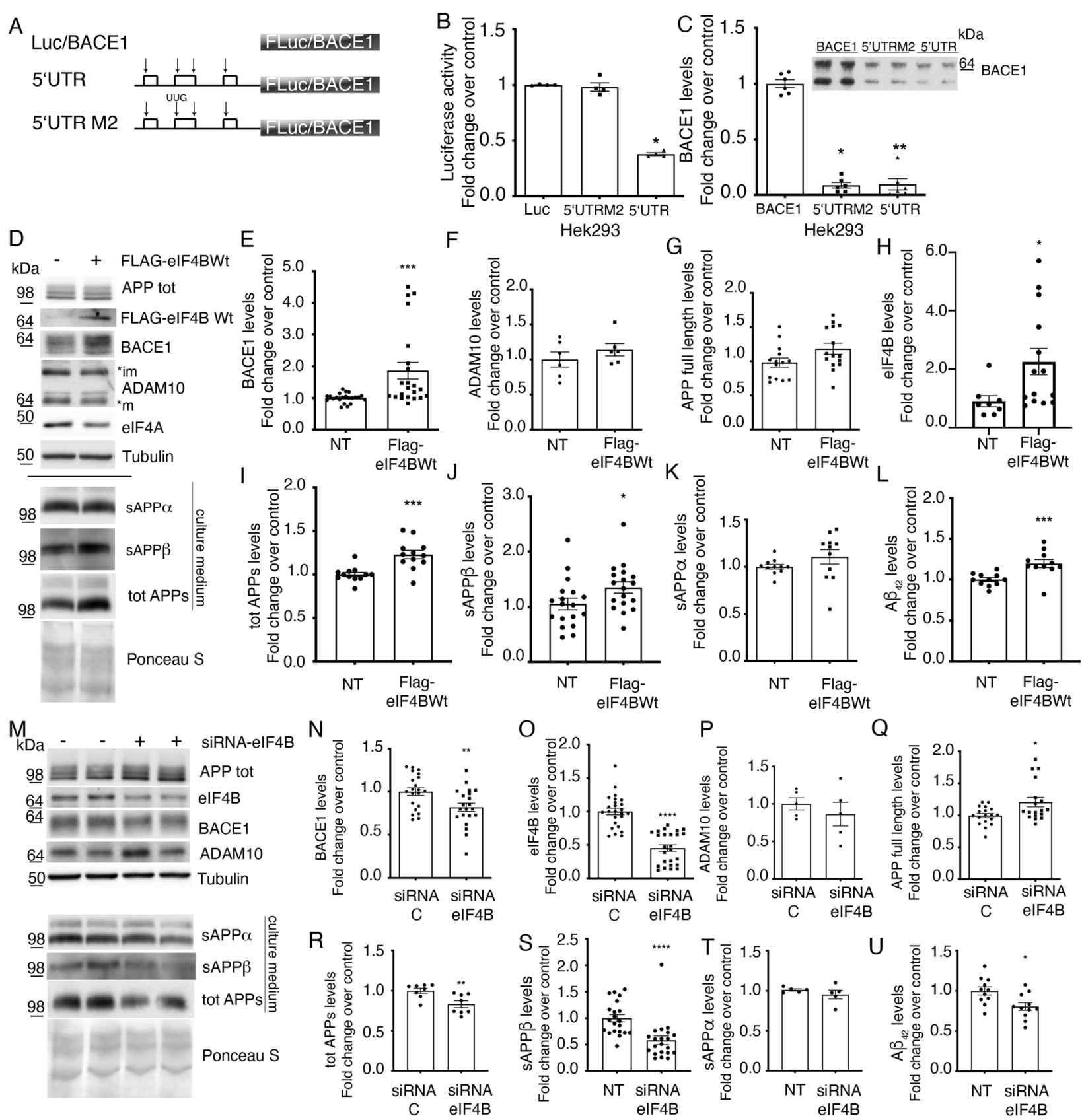

Fig. 1 The presence of BACE1 ORF reinforces the translational inhibition of the $\mathbf{5}^{\prime} \mathbf{U T R}$. A Schematic representation of the transfected constructs, containing Firefly luciferase (FLuc) or BACE1 as reporter gene. White boxes represent uORFs and arrows uAUGs. Mutation of the 2nd UAUG to UUG is indicated. B Luciferase activity measured in total cell extracts of HEK293 cells, co-transfected with the indicated constructs and a plasmid encoding the renilla luciferase. The Firefly Luciferase activity was normalized on renilla luciferase activity to account for differences in transfection efficiencies and data represent the mean \pm SEM of at least three independent experiments, expressed as fold change over control (luciferase). C Quantification of BACE1 levels by western blot (inset) in total cell extracts of HEK293 cells, co-transfected with the indicated constructs and a plasmid encoding Firefly luciferase, to normalize for transfection efficiency. Total cell extracts were subjected to luciferase activity measurement and to SDS-PAGE followed by western blot analysis with anti-BACE1 antibody. Blots were then stripped and reincubated with anti-Calnexin antibody as loading control. The intensities of BACE1 band signals were quantified and normalized for loading and for transfection efficiency (on luciferase activity). Results are presented as mean \pm SEM of at least three independent experiments, with protein levels shown as fold change over control (BACE1). D-T elF4B overexpression or silencing modulates the expression of BACE1. Hippocampal neurons were transfected for $96 \mathrm{~h}$ either (D) with wild-type elF4B (FLAG-elF4BWt) or an empty vector (NT) or (L) with a control or an elF4B siRNA pool. E-L; N-T Representative western blot and quantification of the indicated proteins are shown. BACE1, ADAM10, elF4B, full-length APP (lysate), total soluble APP, soluble APP $\alpha$, or $\beta$ (culture medium) signals were quantified and normalized for loading (Tubulin for cell extracts, Ponceau S staining for cell culture supernatants). H Overexpressed elF4B levels in transfected neurons were quantified as the sum of endogenous and overexpressed protein. L, $\mathbf{U}$ ELISA measurement of $A \beta_{42}$ levels. Results are presented as mean \pm SEM of at least three independent experiments, with protein levels shown as fold change over control (cells transfected with empty vector or with control siRNA pool). Statistical significance was calculated using Kruskal-Wallis one-way analysis of variance followed by Dunn's post hoc test $(\mathbf{B}, \mathbf{C})$, two-tailed Student's $t$-test $(\mathbf{J}, \mathbf{N}, \mathbf{R}, \mathbf{U})$ or Mann-Whitney $\mathbf{U}$ test $(\mathbf{E}, \mathbf{H}, \mathbf{I}, \mathbf{L}, \mathbf{O}, \mathbf{Q}, \mathbf{S})(\mathbf{B}: n=4 p=0.0145 ; \mathbf{C}: n=4 p=0.0145$; E: $n=10 p=0.0003 ; \mathbf{H}: n=8 p=0.0113 ; \mathbf{I}: n=8 p=0.0005 ; \mathbf{J}: n=8 p=0.0485 ; \mathbf{L}: n=8 p=0.0006 ; \mathbf{N}: n=12 p=0.0082 ; \mathbf{0}: n=12 p<0.0001 ;$ Q: $\left.n=12 p=0.0499 ; \mathbf{R}: n=8 p=0.0066 ; \mathbf{S}: n=8 p<0.0001 ; \mathbf{U}: n=8 p=0.0101 .{ }^{*} P<0.05 ;{ }^{* *} P<0.01 ;{ }^{* * *} P<0.001 ;{ }^{* * *} P<0.0001\right)$. 


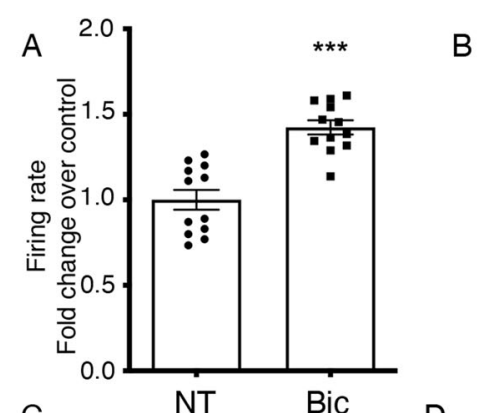

B
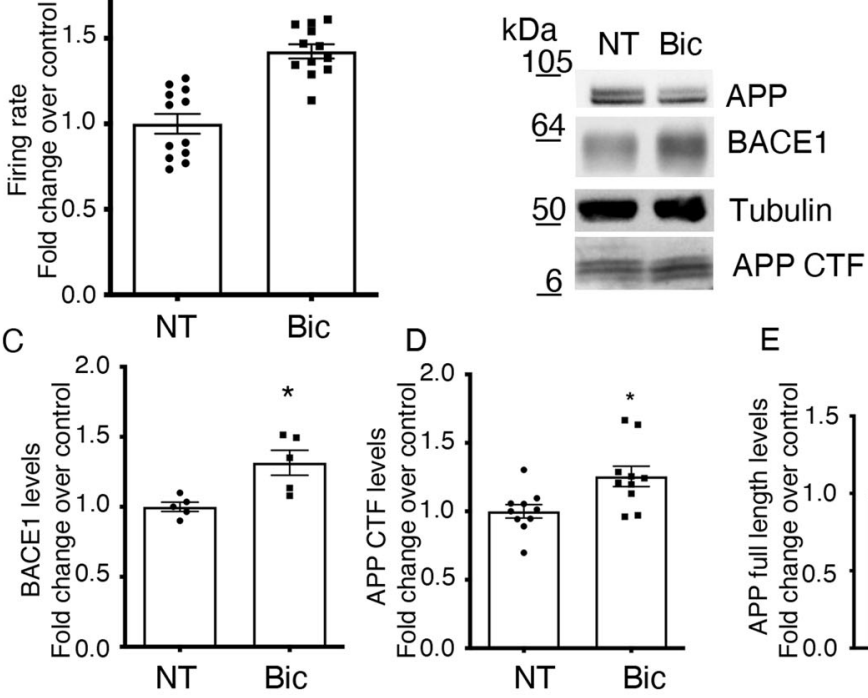

E
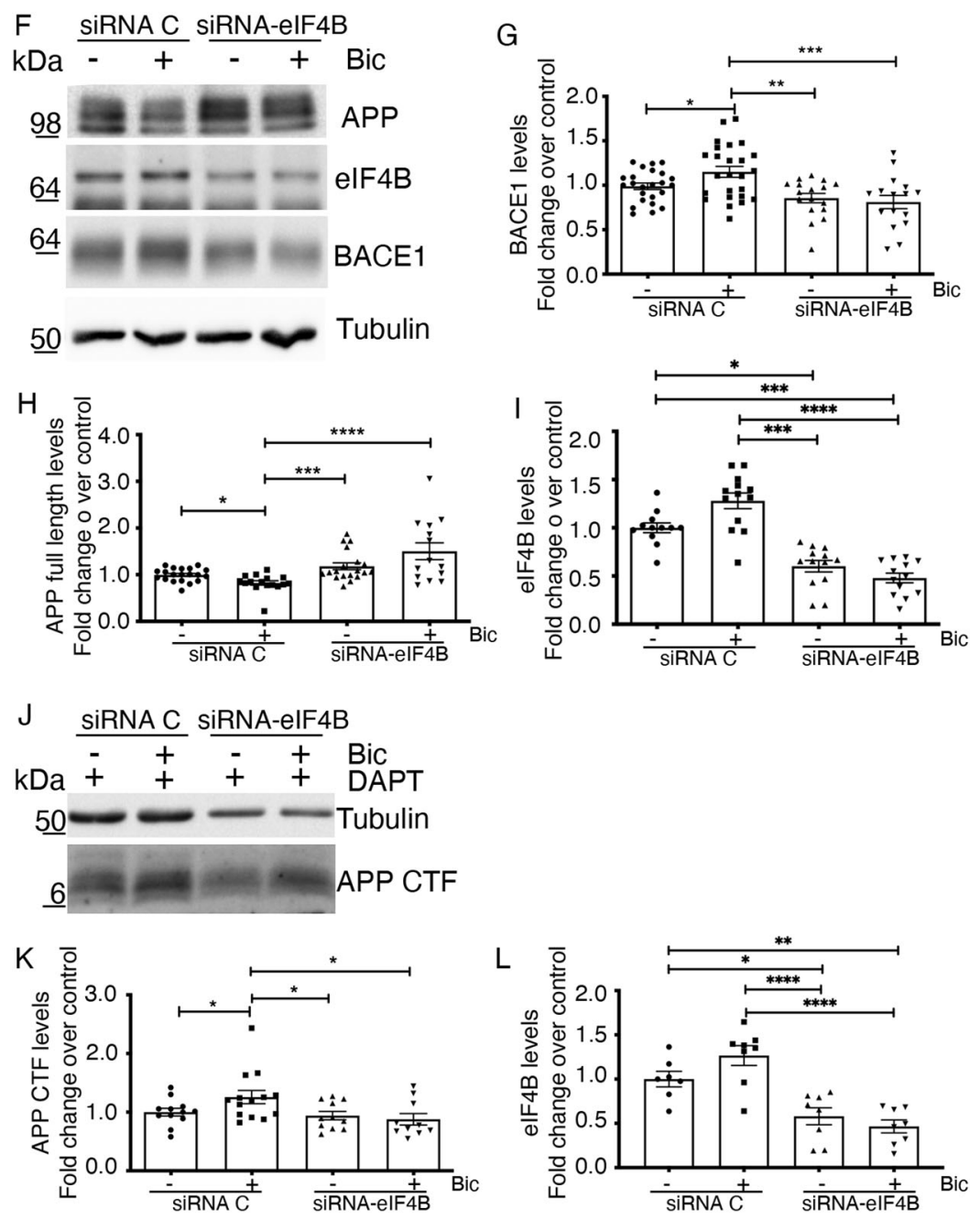

Neurons around $A \beta$ plaques are reported to be in a hyperactive state $[24,25]$ and to express high levels of BACE1 [22, 51]. In addition, soluble $A \beta_{42}$ has been shown to promote neuronal hyperexcitability $[52,53]$, while soluble $A \beta$ oligomers increased BACE1 levels $[54,55]$. To evaluate a possible role of elF4B in the $A \beta$ mediated BACE1 upregulation, we treated mature hippocampal neurons with oligomeric $A \beta(2.5 \mu \mathrm{M}$ for $2 \mathrm{~h})$. In this respect, our data confirmed previous reports, with neurons exposed to soluble oligomeric $A \beta$ species showing an upregulation of BACE1 (Fig. 3l, J). More interestingly, these neurons also showed higher levels of 
Fig. 2 Neuronal activity upregulates BACE1 expression via elF4B. A Average action potential firing rate of neurons treated or not with $10 \mu \mathrm{M} \mathrm{Bic}$ for $20 \mathrm{~min}$ as measured by microelectrode array recordings as described in the "Experimental procedure" section; B-E Representative western blot and quantification of the indicated proteins from total cell extracts of neurons treated or not with $10 \mu \mathrm{M}$ Bic for $2 \mathrm{~h}$. F-L Representative western blot and quantification of the indicated proteins from total cell extracts of neurons treated or not with $10 \mu \mathrm{M}$ Bic for $2 \mathrm{~h}$ after $96 \mathrm{~h}$ of transfection with the control or elF4B siRNA pool. J-L Representative western blot and quantification of the indicated proteins from neurons treated as in $(\mathbf{F})$ with the addition of a pretreatment of 30 min with the $\gamma$-secretase inhibitor DAPT before administration of Bicuculline. Protein signals were quantified and then normalized for loading (Tubulin). Results are presented as mean \pm SEM of at least three independent experiments, with protein levels shown as fold change over control. Statistical significance was calculated by unpaired two-tailed Student's $t$-test (A, C, D), Mann-Whitney U test (E), one-way ANOVA followed by Newman-Keuls post hoc test (G, K), and Kruskal-Wallis one-way analysis of variance followed by Dunn's post hoc test $(\mathbf{H}, \mathbf{I}, \mathbf{L})(\mathbf{A}: n=12 p=0.0001 ; \mathbf{C}: n=5 p=0.0111 ; \mathbf{D}: n=10 p=$ $0.0105 ; \mathbf{E}: n=16 p=0.0029 ; \mathbf{G}: n=12 p=0.0002 ; \mathbf{H}: n=9 p<0.0001 ; \mathbf{I}: n=9 p<0.0001, \mathbf{K}: n=6 p=0.0244 ; \mathbf{L}: n=6 p<0.0001 ;{ }^{*} P<0.05 ;{ }^{* *} P<$ $\left.0.01 ;{ }^{* * *} P<0.001 ;{ }^{* * *} P<0.0001\right)$.

elF4B phosphorylation at the Ser504 site (Fig. 3I, K). Silencing (with siRNAs) or pharmacological inhibition of Casein Kinase before oligomeric $A \beta$ stimulation prevented the increase in both Ser504 phosphorylation (Fig. 3l, K, L, N) and BACE1 levels (Fig. 3l, J, L, M) providing further evidence of the relevance of this enzyme in the control of BACE1 levels through elF4B phosphorylation.

Upregulation of elF4B phosphorylation in AD mouse models The role of elF4B in the regulation of BACE1 expression was further investigated in vivo, using two commonly explored $A D$ mouse models. We evaluated eIF4B and BACE1 levels by western blot and immunohistochemistry in brains of APPPS1 mice [56] at two time points: 2 months, representative of a stage with scarce pathology and 6 months, representing fully established $A D$ pathology. Similarly, as demonstrated in vitro, our in vivo analysis also shows a clear correlation between the increase in elF4B phosphorylation and BACE1 expression (Fig. 4A-C). At 6 months, elF4B phosphorylation was elevated at Ser504 site (Fig. 4A, C) and was paralleled by an increase in the levels of CK2 and AKT phosphorylation in Ser473 (Fig. 4D-F).

We then moved to analyze elF4B and BACE1 localization around $A \beta$ plaques on contiguous sections of APPPS1 mice brains. Interestingly, elF4B and BACE1 expression could be detected around $A \beta$ plaques (Fig. $4 G, H$ ), with a similar pattern (Fig. $4 \mathrm{I}, \mathrm{J}$ ). The same kind of immunolocalization was observed in neurons labeled with the antibody against S504-elF4B (Fig. 4K).

We further validated this result on brains of 2 and 6 months old $A p p^{N L-G-F}$ mice, a knock-in animal model characterized by endogenous levels of APP and a humanized $A \beta$ sequence where human $A D$ mutations have been introduced [57]. In this $A D$ model at 6 months, an increase in elF4B phosphorylation was accompanied by an elevation in BACE1 expression levels (Fig. S4A-C). The levels of CK2 were also increased at the 6 months time point (Fig. S4A, D, F), with no changes in the levels of $S 473$ phosphorylated AKT or pERK (Fig. S4A, E, F). Also in the App ${ }^{N L-G-F}$, the pattern of elF4B localization around plaques closely resembled the distribution of BACE1 around $A \beta$ plaques (Fig. S5A-D), with some dystrophic neurites in the plaque vicinity displaying also higher levels of Ser504-elF4B phosphorylation (Fig. S6).

Altogether, our analysis of $A D$ models strengthens a role for elF4B in the regulation of BACE1 expression that is known to be found increased in the dystrophic neurites surrounding the $A \beta$ plaques.

\section{Treatment of organotypic brain slice cultures from APPPS1 mice with CK inhibitors reduces BACE1 levels}

Organotypic brain slices from an AD mouse model were reported to develop some AD-like features in culture [58]. Although it is known that culturing of neonatal organotypic brain slices from $A D$ mice does not recapitulate $A \beta$ plaque deposition, likely due to efficient $A \beta$ clearance [59-61], some of the AD-like features can be studied using this ex vivo model. Therefore, we decided to evaluate the effect of CK inhibition in this type of experimental model, which is more representative of the physiopathological condition. The effect of CK inhibitors $(10 \mu \mathrm{M}$ D4476 + $25 \mu \mathrm{M}$ TBB; 1 -week treatment) was evaluated on mouse organotypic corticohippocampal brain slices obtained from P8 APPPS1 mice cultured for 18-20 days. To exclude the possibility that this prolonged treatment had toxic effects on the organotypic cultures, we measured lactate dehydrogenase (LDH) release into the culture medium: neither D4476 nor TBB significantly affected total LDH release (Supplementary Fig. S7), indicating that CK inhibitors do not cause toxicity in cultured brain slices at these concentrations. The treatment with the CK inhibitors significantly reduced the levels of elF4B phosphorylation on Ser504 (Fig. 5A, B) as well as the levels of BACE1 protein (Fig. 5A, C) and $A \beta_{42}$ levels (Fig. 5D), confirming the data obtained in primary neuronal cultures and in the APPPS1 mice brains.

\section{Upregulation of elF4B expression and phosphorylation in human AD brains}

To further explore the relevance of elF4B-dependent BACE1 upregulation in $A D$ patients, we performed an experiment on formalin-fixed, paraffin-embedded tissues obtained from human $\mathrm{AD}$ and control hippocampi $(n=3)$. Figure 6 shows representative sections that confirm that both total and Ser504-phosphorylated elF4B are increased in the presence of $A \beta$ pathology. Furthermore, the non-phosphorylated protein staining appears stronger in the pyramidal layer while phospho-elF4B signal appears more enriched in the dendritic regions (Fig. 6G-I).

\section{DISCUSSION}

BACE1 translation is known to be regulated [10, 62]. It has been shown that the $5^{\prime}$ UTR of BACE1 harbours an intrinsic repressing activity of translation, which was initially ascribed to the contribution of UAUGs and upstream open reading frames (uORFs) combined with the structural hindrance given by the high GCcontent $[30,42,43]$. Our data confirm the inhibitory role of the $5^{\prime}$ UTR on BACE1 translation, showing however that BACE1 coding sequence or, at least, the region at the 5'UTR-ORF border, has relevant inhibitory properties that are potentially related to structural elements. This hypothesis is substantiated by the absence of a translational rescue operated by the second UAUG mutation, when BACE1 coding sequence was used as a reporter. In fact, in Hek293 cells, the BACE1 coding sequence appears to introduce an additional inhibitory element that cannot be overcome by the mutation of the second UAUG. This additional inhibitory effect could be due to the formation of an even more complex structured region, as suggested by in silico secondary structure prediction, or the binding of specific cellular factors; both possibilities are worthy of further investigation.

BACE1 translational repression, which is constitutively active, is expected to be relieved under specific conditions. A likely possibility is that stimuli able to modulate BACE1 translation may influence the helicase activity of the elF4F complex, thus allowing a better unwinding of the structured $5^{\prime}$ UTR and a more efficient scanning by the small ribosomal subunit. For this reason, 



we focused our attention on elF4B, whose role in the regulation of translation of structured transcripts has recently gained attention $[40,63]$. elF4B function in the translation process is influenced by phosphorylation $[64,65]$ and we have recently shown that increase in synaptic activity changes the phosphorylation state of elF4B, in a way that both its interaction with the translation initiation complex and its localization at the synaptic sites are favored [41].

Considering that not only elF4B mRNA and protein $[66,67]$, but also BACE1 protein [22] are present at synapses, we investigated 
Fig. 3 CK2 silencing or inhibition downregulates BACE1 expression induced by neuronal activity or A $\boldsymbol{\beta}$ challenge. Representative western blot and quantification of the indicated proteins in extracts from primary hippocampal neurons: A-E treated or not with $10 \mu \mathrm{M}$ Bic for $2 \mathrm{~h}$, without or with pretreatment with the CK2 siRNA pool for $96 \mathbf{h} ; \mathbf{F}$, G pre-treated or not for $4 \mathrm{~h}$ with a CK2 inhibitor (25 $\mu \mathrm{M}$ TBB) alone or in combination with a CK1 inhibitor (10 $\mu \mathrm{M}$ D4476, $25 \mu \mathrm{M}$ TBB) and analyzed after treatment with $10 \mu \mathrm{M}$ bicuculline (Bic) for 2 h; I-K pre-treated or not for $4 \mathrm{~h}$ with a CK2 inhibitor $(25 \mu \mathrm{M}$ TBB) alone or in combination with a CK1 inhibitor $(10 \mu \mathrm{M}$ D4476, $25 \mu \mathrm{M}$ TBB) and analyzed after treatment with $2.5 \mu \mathrm{M}$ Oligomeric $A \beta(A \beta O)$ for $2 \mathrm{~h}$; L-N treated or not with $2.5 \mu \mathrm{M}$ Oligomeric $A \beta(A \beta O)$ for $2 \mathrm{~h}$, without or with pretreatment with the CK2 siRNA pool for $96 \mathrm{~h}$. Protein levels were quantified, normalized for loading (Tubulin), and then shown as fold change over control (untreated neurons). Phosphorylated elF4B levels are normalized against total elF4B, then for loading (Tubulin) and shown as fold change over control (untreated neurons). Data are shown as mean \pm SEM of at least three independent experiments for each treatment. Statistical significance was calculated by one-way ANOVA followed by Tukey's (B), Dunnett (C, H, N), Newman-Keuls post hoc test (G, M), nonparametric Kruskal-Wallis one-way analysis of variance followed by Dunn's post hoc test (E, J, K) (B: $n=4 p=0.0007 ; \mathbf{C}: n=4 p=0.00410 ; \mathbf{E}: n=4 p=$ 0.0013; G: $n=5 p<0.0001 ; \mathbf{H}: n=5 p=0.0004 ; \mathbf{J}: n=5 p=0.0071 ; \mathbf{K}: n=5 p=0.0096 ; \mathbf{M}: n=4 p=0.0288 ; \mathbf{N}: n=4 p=0.0004 ;{ }^{*} P<0.05,{ }^{* *} P<$ $0.01, * * * P<0.001)$.

whether, upon neuronal activation, elF4B phosphorylation was able to boost the translation of BACE1.

Our results demonstrate that a moderate increase in spontaneous neuronal activity, obtained by antagonizing the inhibitory connections of an in vitro neuronal network, triggers the phosphorylation of elF4B and, in turn, enhances BACE1 expression, promoting APP processing. Interestingly, only the amyloidogenic pathway appeared to be potentiated while neither APP levels nor non-amyloidogenic processing were affected. All these findings draw the attention to the influence exerted by the neuronal activity on BACE1 expression and its synaptic localization.

Neuronal activity is considered a trigger for the amyloidogenic pathway [68-70] and it was shown to promote the interaction between APP and BACE1 [71]. A correlation between altered brain activity and amyloid deposition has already been shown in patients $[72,73]$ and alterations in the activity of specific brain networks, including epileptiform discharges [74], were observed during the early phase of AD [73]. Altogether, a control of BACE1 expression in the synaptic context might offer the possibility to intervene on $A \beta$ deposition without influencing the physiological events downstream of the APP processing pathway.

Starting from this complex scenario, here we show that both an increase in neuronal network activity and administration of soluble forms of $A \beta$ promote elF4B phosphorylation, BACE1 expression and APP processing. The physiological relevance of a proper control of this pathway is further supported by the evidence that elF4B phosphorylation is increased in the brain of APPPS1 and APP-KI mice. Even more striking is the fact that this occurs also in the brain of AD patients. More data will be necessary to strengthen this finding and to determine whether the increase in phospho-elF4B is the main cause of BACE1 elevation in $A D$ mice.

This body of evidence fits with a general scenario in which increased soluble $A \beta$ levels and/or subtle alterations of the neuronal activity sustain CK2 activation and elF4B phosphorylation at the synapse, possibly in an early phase of the disease, with ensuing increase in BACE1 expression and $A \beta$ production. With disease progression, the accumulation of elF4B and BACE1 around plaques is expected to constitute the premise of a vicious circle of increased $A \beta$ production followed by elF4B hyper-phosphorylation and BACE1 elevation. In this respect, it has recently been shown that $A \beta_{42}$ is able to promote changes in axonal protein translation [75] and that local protein synthesis at synapses was found altered in a mouse model of $A D$ [76].

Our hypothesis of a elF4B-dependent regulation of BACE1 expression is also strengthened by the recent observation that elF4B phosphorylation plays a role in the modulation of BACE1 levels promoted by matrix metalloproteinase 13 [77].

Since BACE1 transport and subcellular localization are also a critical step in amyloidogenesis [78, 79], we cannot exclude that elF4B and BACE1 accumulation in proximity of plaques could depend on mechanisms other than local translational regulation, such as an alteration of the axonal transport, an early sign of $A D$ pathology [80].

BACE1 inhibition was considered the most promising strategy for lowering $A \beta$ burden in the brain of $A D$ patients, but the adverse effects that led to the discontinuation of several clinical trials fell short of everybody's expectations [18-20]. However, in those studies, BACE 1 activity was inhibited up to $90 \%$ in patients with already established $A \beta$ deposition.

It remains to be established if a partial reduction of BACE1 levels, possibly before the appearance of amyloid pathology, may prevent these detrimental side effects, maintaining the cleavage of substrates other than $A \beta$ and preserving the physiological functions of the enzyme.

Our findings provide a novel view on how BACE1 expression is regulated by synaptic activity, identifying CK2 and elF4B as key players. The possibility to use CK2 inhibitors to specifically control BACE1 increase, upon synaptic activation or presence of excess $A \beta$, may thus represent a therapeutic target different from those currently assessed in $A D$ and with a disease-modifying potential. Testing CK2 inhibition in vivo in a mouse model of $A D$ will be a necessary step to take: CK2 is a pleiotropic kinase and we are aware that its inhibition poses other relevant questions on possible side effects. However, the fact that specific CK2 inhibitors are currently used in phase I and II clinical trials for cancer therapy, may significantly accelerate the possibility to test the potential of these drugs to prevent and/or treat $A D$ in its early phase. Last, the possibility to use gene therapy protocols (i.e., nasal delivery of viral particles) or specific delivery systems (conjugation with nanoparticles) aimed at delivering shRNAs against CK2 or elF4B in a cell specific and temporally restricted way could open new interesting possibilities to selectively target this pathogenetic processes in AD.

\section{EXPERIMENTAL PROCEDURE}

References for the "Experimental procedure" section are reported in the Supplementary material file.

\section{Animals}

Hemizygous APPPS1 mouse line overexpressing human APPKM670/671NL and PS1L166P under the control of the Thy1 promoter [1], homozygous $A p p^{N L-G-F}$ mouse line [2], and the corresponding C57BL/6J (WT) line were used in this study. Mice were group-housed under specific pathogen-free conditions. Mice had access to water and standard mouse chow (Ssniff ${ }^{\oplus}$ $\mathrm{Ms}-\mathrm{H}$, Ssniff Spezialdiäten $\mathrm{GmbH}$, Soest, Germany) ad libitum and were kept under a 12/12 h light-dark cycle in IVC System. All animal experiments were performed in compliance with the German animal welfare law and have been approved by the government of Upper Bavaria. All animal experiments have been carried out following the ARRIVE guidelines and in accordance with the EU Directive 2010/63/EU for animal experiments. For the 2 months time point 6 animals per group 

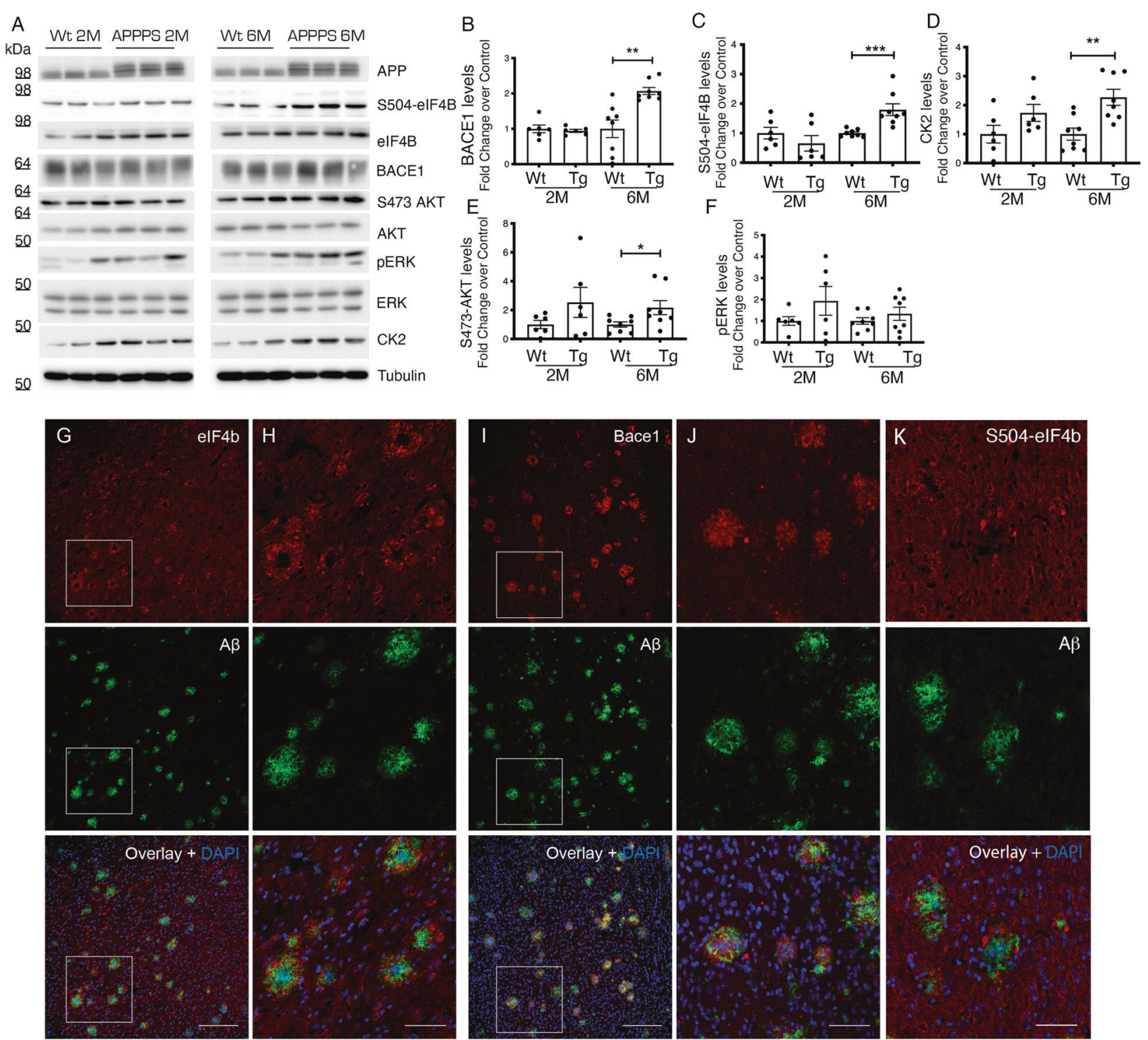

Fig. 4 Increased elF4B expression and phosphorylation in the brains of APPPS1 mice. A-F Representative western blot (A) and quantification (B-F) of the indicated proteins in extracts from $2(2 \mathrm{M})$ or $6(6 \mathrm{M})$ months old brains from APPPS1 (APPPS) or wild-type (Wt) mice. Protein levels are shown as fold change over control (Wt mice). Levels of phosphorylated proteins are normalized against the corresponding total protein, then for loading (Tubulin) and shown as fold change over control (Wt mice). Statistical significance was evaluated by unpaired two-tailed Student's $t$-test. G-J Immunohistochemical analysis of elF4B expression in 6-month-old APPPS1 cortices immunostained for elF4B (red: G, H) or BACE1 (red: I, J) or S504-elF4B (K) in combination with A $\beta$ (green) revealed a localization of elF4B in close proximity of plaques, with a pattern similar to the distribution of BACE1 in dystrophic neurites. Second and fourth column panels are higher magnification images of boxed regions. Scale bars: G, I, $50 \mu \mathrm{m}, \mathbf{H}, \mathbf{J}, \mathbf{K} 150 \mu \mathrm{m}$ ( 2 months $n=6$ mice for each genotype; 6 months $n=8$ mice for each genotype; B: $\left.p=0.0019 ; \mathbf{C}: p=0.0003 ; \mathbf{D}: p=0.0047 ; \mathbf{E}: p=0.0207 ;{ }^{* *} P<0.01,{ }^{* * *} P<0.001,{ }^{* * * *} P<0.0001\right)$.

were used (Wt, APPPS1, and $A p p^{N L-G-F}$ ), 4 females and 2 males for each genotype. For the 6 months time point 8 animals per group were used, 5 females and 3 males for each genotype.

\section{Human tissue}

Formalin-fixed, paraffin-embedded Human AD brains were obtained from the Biobank of the Institute of Medical Genetics and Pathology, Basel University Hospital, Basel, Switzerland.

\section{Materials}

Cell culture media and reagents, if not otherwise stated, were from Gibco (ThermoFisher Scientific, Carlsbad, CA, USA). Plates and flasks were from Nalge Nunc (Rochester, NY, USA). Petri dishes were from Falcon BD (Franklin Lakes, NJ, USA).
4-(4-(2,3-Dihydrobenzo[1,4]dioxin-6-yl)-5-pyridin-2-yl-1H-imidazol-2-yl)benzamide (D4476), 4,5,6,7-Tetrabromo-2-azabenzimidazole, 4,5,6,7-Tetrabromobenzotriazole (TBB) and other chemicals were from Tocris (Bristol, UK) or Merck-Sigma (Darmstadt, Germany).

\section{Cell culture}

The Institutional Animal Care and Use Committee of the San Raffaele Scientific Institute approved the animal use procedures. Primary cultures of hippocampal neurons were prepared according to [3] from 2- to 3-day-old Sprague-Dawley rats. Briefly, after subdivision of hippocampi into small sections, the tissue was incubated into Hank's solution containing $3.5 \mathrm{mg} / \mathrm{ml}$ trypsin type IX (Merck-Sigma) and $0.5 \mathrm{mg} / \mathrm{ml}$ DNase type IV (Calbiochem, La 


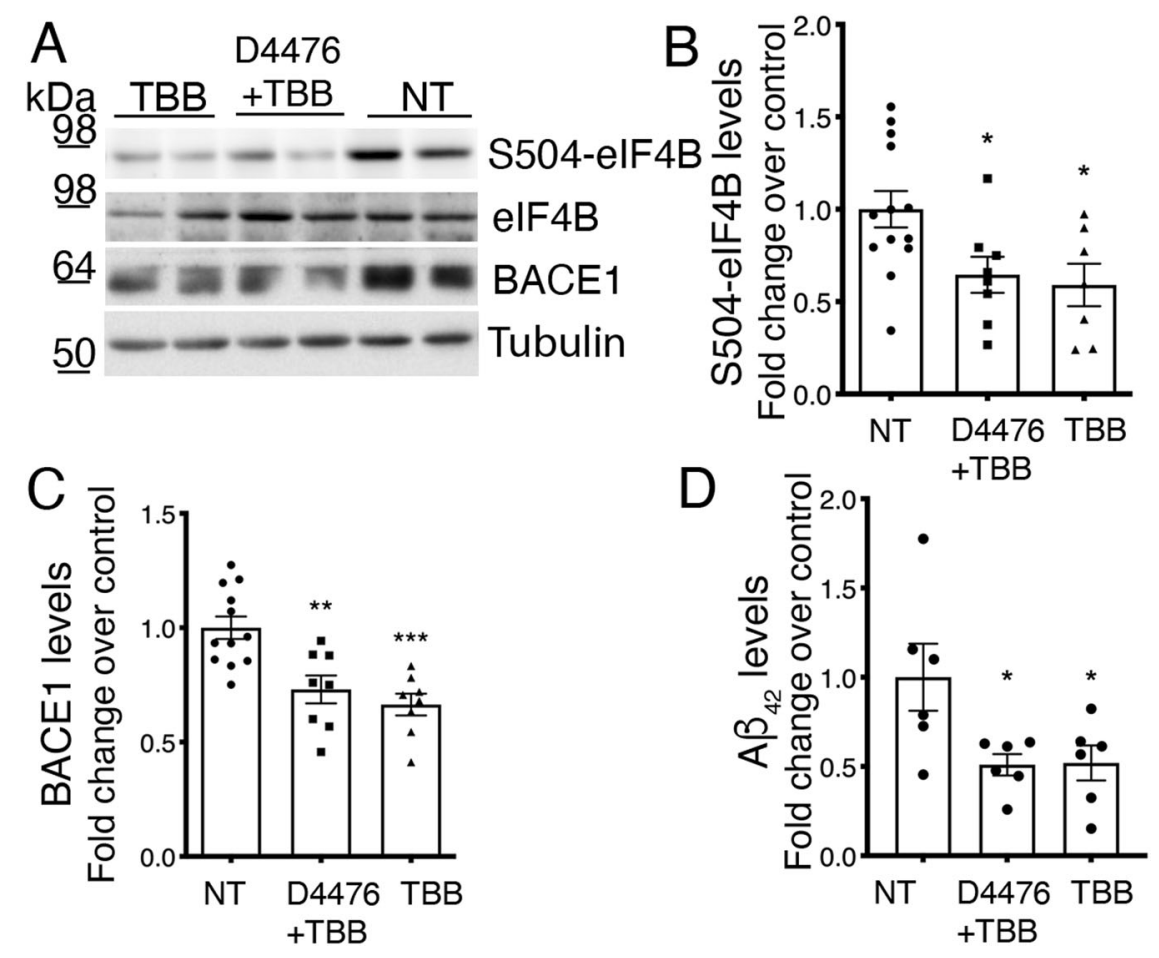

Fig. 5 Casein Kinase inhibition lowers BACE1 levels in organotypic slices from APPPS1 mice. A-C Western blot analysis for elF4B total or phosphorylated (S504), BACE1, and Tubulin performed on extracts from APPPS1 brain slices treated with CK2 inhibitor (TBB), alone or in combination with CK1 inhibitor (D4476+TBB) or left untreated (NT). Protein levels are shown as fold change over control (untreated slices). Levels of phosphorylated proteins are normalized against the corresponding total protein, then for loading (Tubulin) and shown as fold change over control (untreated slices). D ELISA measurement of $A \beta_{42}$ levels in culture supernatants of slices treated as in (A). Slices were treated for 7 days before analysis. Statistical significance was evaluated by one-way ANOVA followed by Dunnett post hoc test (B: $n=6 p=$ $0.0161 ; \mathbf{C}: n=6 p=0.0002)$ or Tukey post hoc test (D: $n=6 p=0.0235)$.

Jolla, CA, USA) for $5 \mathrm{~min}$. The pieces were then mechanically dissociated in a Hank's solution supplemented with $12 \mathrm{mM}$ $\mathrm{MgSO}_{4}$ and $0.5 \mathrm{mg} / \mathrm{ml}$ DNase IV. After centrifugation, cells were plated onto poly-ornithine-coated coverslips and maintained in minimal essential medium supplemented with $20 \mathrm{mM}$ glucose, B27 (Life Technologies, Carlsbad, CA, USA), 2 mM glutamax, 5\% fetal clone III (FCIII; Hyclone, South Logan, UT, USA) and $5 \mu \mathrm{M} 1-$ $\beta$-D-cytosine-arabinofuranoside (Merck-Sigma). Cultures were maintained at $37^{\circ} \mathrm{C}$ in a $5 \% \mathrm{CO}_{2}$ humidified incubator and used between 7 and 15 days after plating.

Primary cultures of cortical astrocytes were established from 1- to 2-day-old Sprague-Dawley rats (Charles River, Wilmington, MA, USA) according to [4]. Briefly, cortices were freshly dissected, cut into small pieces, and washed in Hank's balanced salt solution supplemented with $10 \mathrm{mM}$ Hepes/Na pH 7.4, $12 \mathrm{mM} \mathrm{MgSO}_{4}$, $50 \mathrm{U} / \mathrm{ml}$ penicillin, and $50 \mu \mathrm{g} / \mathrm{ml}$ streptomycin (Gibco). Tissue dissociation was performed with trypsin $(2.5 \mathrm{mg} / \mathrm{ml}$ trypsin type IX, in the presence of $1 \mathrm{mg} / \mathrm{ml}$ DNase; $10 \mathrm{~min}$ at $37^{\circ} \mathrm{C}$ ) in two subsequent steps without mechanical trituration and terminated by 1:1 dilution in serum-containing medium. After centrifugation $(50 \times g, 15 \mathrm{~min})$ cells were plated in $75-\mathrm{cm}^{2}$ flasks with Minimum Essential Medium Eagle with Earle's balanced salt solution, supplemented with $10 \%$ donor horse serum, $33 \mathrm{mM}$ glucose, $2 \mathrm{mM}$ glutamax (Gibco), $50 \mathrm{U} / \mathrm{ml}$ penicillin and $50 \mu \mathrm{g} / \mathrm{ml}$ streptomycin, and kept at $37^{\circ} \mathrm{C}$ in a humidified $5 \% \mathrm{CO}_{2}$ atmosphere. Two steps of overnight shaking at $230 \mathrm{rpm}$ were performed to induce selective detachment of microglia. After reaching confluence, astrocytes were trypsinized and re-plated onto poly-lysine-coated plastic multiwells. Astrocytes were used within 3 days after re-plating.

Hek293 cells were maintained in Dulbecco's modified Eagle's medium supplemented with $10 \%$ FCIII, $2 \mathrm{mM}$ glutamine, $10 \mathrm{mM}$
Na pyruvate, $50 \mathrm{U} / \mathrm{ml}$ penicillin, and $50 \mu \mathrm{g} / \mathrm{ml}$ streptomycin and kept at $37^{\circ} \mathrm{C}$ in a humidified $5 \% \mathrm{CO}_{2}$ atmosphere. Cells were routinely tested for mycoplasma contamination.

\section{Expression plasmids}

Constructs used for transfections were (i) pcDNA3.1-BACE1 (containing the human BACE1 coding sequence obtained by PCR and cloned EcoRI-Xhol); (ii) pcDNA3.1-5UTR-BACE1 (containing the human BACE1 coding sequence obtained by PCR and cloned EcoRI-Xhol, downstream of the BACE1 5'UTR, cloned KpnlXhol from T3pA-B1x-[5]); (iii) pcDNA3.1-5'UTRM2-BACE1 (containing the human BACE1 coding sequence obtained by PCR and cloned EcoRI-Xhol, downstream of the BACE1 5'UTR, cloned KpnlXhol from T3pA-B1-mut2-[5]); (iv) pcDNA3.1-Luc+ (containing the firefly luciferase coding sequence cloned Xhol-Notl from pT3a - [5]); (v) pcDNA3.1-5'UTR-Luc + (containing the firefly luciferase coding sequence cloned Xhol-Notl from pT3a, downstream of the BACE1 5'UTR, cloned Kpnl-Xhol from T3pA-B1x-[5]); (vi) pcDNA3.1-5'UTRM2-Luc + (containing the firefly luciferase coding sequence cloned Xhol-Notl from pT3a, downstream of the BACE1 5'UTR, cloned Kpnl-Xhol from T3pA-B1-mut2-[5]); (vii) pcDNA3Flag4Bwt (kind gift of J. Hershey).

\section{Cell transfection}

HEK293 cells or cortical astrocytes were plated the day before transfection at $50 \%$ of confluence in poly-L-Lysine (Sigma-Aldrich) treated 6-well plates and then transfected with $1.8 \mu \mathrm{g}$ of DNA $(1.5 \mu \mathrm{g}$ of plasmid encoding WT-eIF4B and $300 \mathrm{ng}$ of plasmid encoding GFP) and $4 \mu$ l of Lipofectamine 3000 (Life Technologies), according to the manufacturer's instructions. After $24 \mathrm{~h}$ cells were collected, lysed in lysis buffer (phosphate-buffered saline containing $10 \mathrm{mM}$ EDTA/Na, 2\% NP-40, 0.2\% SDS, CLAP, $1 \mathrm{mM} \mathrm{NaF}, 2 \mathrm{mM}$ 


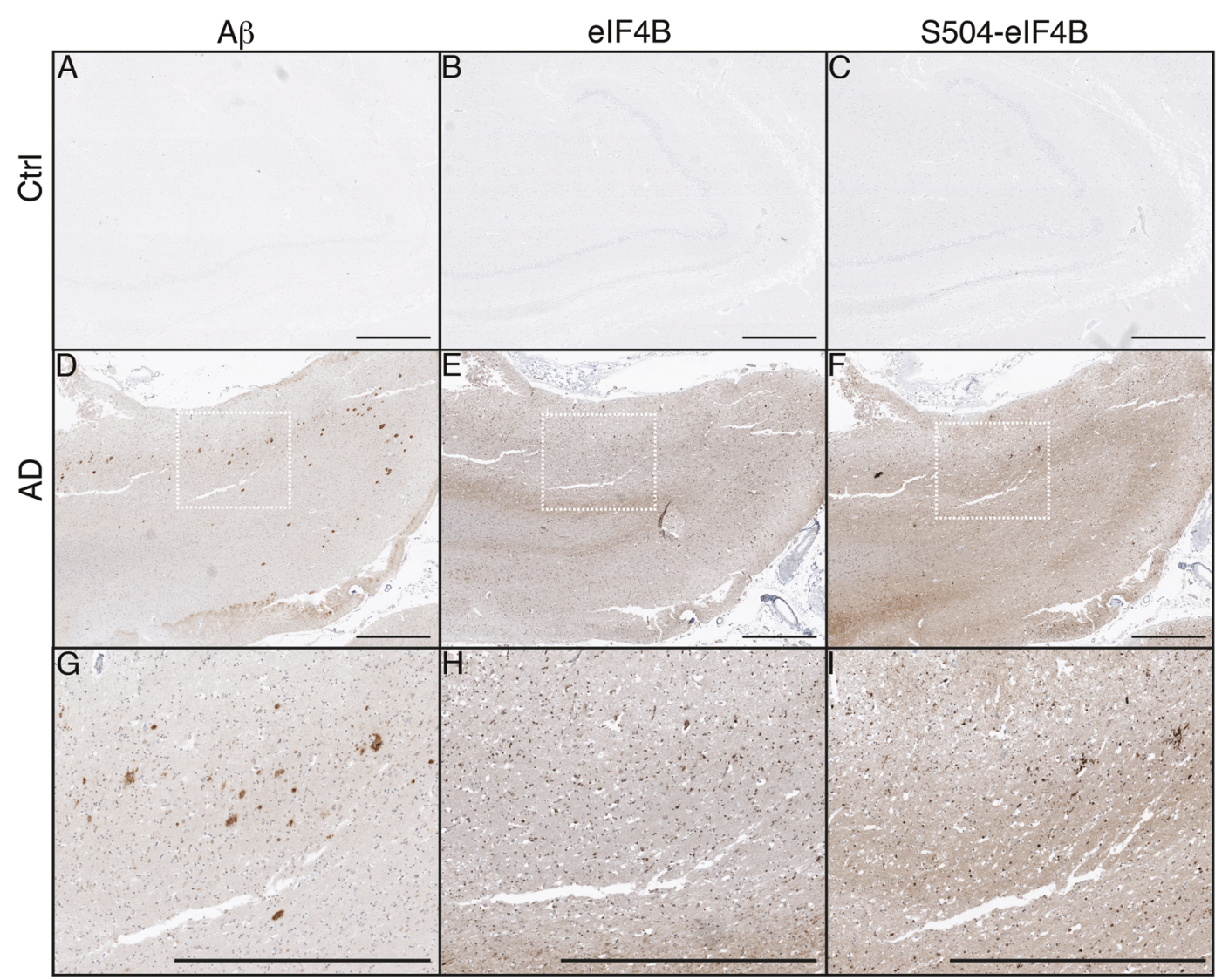

Fig. 6 Expression and phosphorylation of elF4B are increased in human AD hippocampi. Representative immunohistochemical analysis of human $A D$ and control hippocampal sections $(n=3)$ stained for $A \beta(\mathbf{A}, \mathbf{D}, \mathbf{G})$, total $(\mathbf{B}, \mathbf{E}, \mathbf{H})$, and phospho Ser504 elF4B (C, F, I) showing that both total and phosphorylated elF4B are increased in the presence of $A \beta$ pathology. $\mathbf{G}-\mathbf{I}$ panels are higher magnification images of boxed regions. Scale bars: $1 \mathrm{~mm}$.

$\mathrm{Na}_{3} \mathrm{VO}_{4}$ ), total protein content determined with the BCA reagent and then used for luciferase activity detection or directly analysed by western blot.

Primary hippocampal neurons (4 days in vitro) were transfected with $100 \mathrm{pmol}$ of siRNA (ON-TARGETplus NON-TARGETING rat POOL, ON-TARGETplus SMART POOL against rat elF4B and ONTARGETplus SMART POOL against rat CK2 alpha - ThermoFisher Scientific) and $4 \mu \mathrm{l}$ of Lipofectamine 3000 (Life Technologies), according to the manufacturer's instructions. At 8 days in vitro neurons were collected, lysed in PBS (containing $10 \mathrm{mM}$ EDTA/Na, $1 \%$ TX-100, and protease inhibitor cocktail), total protein content determined with the BCA reagent (ThermoFisher Scientific, Pierce), and then analysed by western blotting.

\section{Luciferase reporter assay}

Firefly luciferase (Fluc) and Renilla luciferase (Rluc) activities were revealed with the Dual-Luciferase reporter assay system (Promega) and measured ( $5 \mathrm{~s}$ readings) using a plate-reading luminometer (Mithras, Berthold). The Rluc reporter gene was used to normalize for differences in transfection efficiency.

Fluc reporter gene was used to normalize for differences in transfection efficiency when the vectors containing the BACE1 coding sequence were used. In this case, Fluc activity was revealed with the Single-Luciferase reporter assay system (Promega) and measured ( $5 \mathrm{~s}$ readings) as described above.

\section{Cellular treatments}

When indicated, bicuculline $10 \mu \mathrm{M}$ (Tocris, Bristol, UK) was added directly in the culture medium, for the specified times. D4476 $10 \mu \mathrm{M}$ and TBB $25 \mu \mathrm{M}$ were added $2 \mathrm{~h}$ before bicuculline or $\mathrm{A} \beta$ oligomers treatment, alone or in combination. $A \beta 42$ oligomers were prepared from a human $A \beta(1-42)$ peptide (Bachem, Bubendorf, Switzerland) stock $2.5 \mathrm{mM}$ in DMSO. To prepare oligomers, $2.5 \mathrm{mM} \mathrm{A} \beta$ DMSO stock was diluted to $50 \mu \mathrm{M}$ in EMEM w/o phenol red and left for $24 \mathrm{~h}$ at $4{ }^{\circ} \mathrm{C}$. Immediately before the experiment, $A \beta$ oligomers were diluted to $2.5 \mu \mathrm{M}$ in culture medium and added to the neurons. Control neurons were treated with the same concentration of DMSO in culture medium.

For detection of APP C-terminal fragments cells were treated, as in [6], with $1 \mu \mathrm{m} \mathrm{N}$-[N-(3,5-difluorophenacetyl)-L-alanyl]-S-phenylglycine t-butyl ester (DAPT) (Merck-Sigma) in DMSO to inhibit gamma-secretase for $15 \mathrm{~min}$ before treatment with Bicuculline.

\section{Western blotting}

About $25 \mu \mathrm{g}$ of proteins were separated by standard SDS-PAGE and transferred onto nitrocellulose membrane. The nitrocellulose filter was stained with Ponceau S $(0.2 \%$ in $3 \%$ trichloroacetic acid) and de-stained with double distilled-water for protein visualization. After $1 \mathrm{~h}$ of blocking with TBST $(10 \mathrm{mM}$ Tris/ $\mathrm{HCl}, 150 \mathrm{mM}$ $\mathrm{NaCl}, 0.1 \%$ Tween-20) containing $5 \%$ bovine serum albumin (Roche Diagnostics, Basel, Switzerland) or skimmed powdered milk, the membranes were incubated overnight with the primary antibodies and, after extensive washing, with horseradish peroxidase-conjugated anti-rabbit or mouse secondary antibody (Bio-Rad, Hercules, CA, USA). For loading controls membranes were stripped in acidic buffer ( $0.2 \mathrm{M}$ glycine, $0.1 \% \mathrm{SDS}, 1 \%$ Tween20, $\mathrm{pH} 2.2$ ) and re-probed with the appropriate antibody. In the cases where stripping was not possible, the same lysates were run simultaneously on duplicate gels, and probed with phospho and total antibodies. 
Proteins were revealed on auto-radiographic films (GE Healthcare, Piscataway, NJ, USA) or by direct acquisition using the Biorad Chemidoc system by Super Signal West Chemiluminescent Substrate (ThermoFisher Scientific, Waltham, MA, USA). Bands were quantified using ImageJ and protein levels normalized against the loading control. Phosphorylated elF4B levels were normalized against total elF4B, then for loading (Tubulin).

The following antibodies were used for western blot: anti-APP (Total APP and 22C11 clone), anti-Flag polyclonal, and antialpha-Tubulin antibodies from Merck (Merck KGaA, Darmstadt, Germany); anti-BACE1, ADAM10, elF4A, elF4B, CK2 alpha, AKT, phospho Ser473 AKT, p44/42 MAPK (Erk1/2), Phospho-p44/42 MAPK (Erk1/2) (Thr202/Tyr204) from Cell Signaling Technology (Danvers, MA, USA); anti-phospho Ser504 from Abcam (Cambridge, UK). Antibodies against mouse soluble APPa (rat mAb A16M 5G11, specific for murine APPsa in culture media, generated by immunization against DAEF GHDSGFEVRHQKC$\mathrm{COOH}$ peptide-[9]) and $\beta$ (mouse mAb BAWT antibody specific for APPs $\beta$ - [10] were a kind gift of Dr. Stephan Lichtenthaler.

\begin{tabular}{|c|c|c|c|c|}
\hline Antibody & Product Number & Concentration & Blocking & Producer \\
\hline elF4B & 3592 & $1: 1000$ & $\begin{array}{l}5 \% \text { BSA } \\
\text { in TBST }\end{array}$ & $\begin{array}{l}\text { Cell Signaling } \\
\text { Technology }\end{array}$ \\
\hline $\begin{array}{l}\text { S504- } \\
\text { elF4B }\end{array}$ & Ab75823 & $1: 3000$ & $\begin{array}{l}5 \% \text { BSA } \\
\text { in TBST }\end{array}$ & Abcam \\
\hline BACE & 5606 & 1:1000 & $\begin{array}{l}5 \% \text { BSA } \\
\text { in TBST }\end{array}$ & $\begin{array}{l}\text { Cell Signaling } \\
\text { Technology }\end{array}$ \\
\hline Total APP & A8717 & $1: 2500$ & $\begin{array}{l}5 \% \text { Milk } \\
\text { in TBST }\end{array}$ & Merck \\
\hline CK2 & 2656 & 1:1000 & $\begin{array}{l}5 \% \text { BSA } \\
\text { in TBST }\end{array}$ & $\begin{array}{l}\text { Cell Signaling } \\
\text { Technology }\end{array}$ \\
\hline S473-AKT & 4060 & 1:1000 & $\begin{array}{l}5 \% \text { BSA } \\
\text { in TBST }\end{array}$ & $\begin{array}{l}\text { Cell Signaling } \\
\text { Technology }\end{array}$ \\
\hline AKT & 4691 & $1: 5000$ & $\begin{array}{l}5 \% \text { BSA } \\
\text { in TBST }\end{array}$ & $\begin{array}{l}\text { Cell Signaling } \\
\text { Technology }\end{array}$ \\
\hline $\begin{array}{l}\text { Phospho- } \\
\text { ERK }\end{array}$ & 4370 & 1:1000 & $\begin{array}{l}5 \% \text { BSA } \\
\text { in TBST }\end{array}$ & $\begin{array}{l}\text { Cell Signaling } \\
\text { Technology }\end{array}$ \\
\hline ERK & 9102 & 1:1000 & $\begin{array}{l}5 \% \text { BSA } \\
\text { in TBST }\end{array}$ & $\begin{array}{l}\text { Cell Signaling } \\
\text { Technology }\end{array}$ \\
\hline $\begin{array}{l}\text { alpha } \\
\text { Tubulin }\end{array}$ & T9026 & 1:6000 & $\begin{array}{l}5 \% \text { Milk } \\
\text { in TBST }\end{array}$ & Merck \\
\hline $22 C 11$ & MAB348 & $1: 1000$ & $\begin{array}{l}5 \% \text { Milk } \\
\text { in TBST }\end{array}$ & Merck \\
\hline elF4A & 2013 & 1:1000 & $\begin{array}{l}5 \% \text { BSA } \\
\text { in TBST }\end{array}$ & $\begin{array}{l}\text { Cell Signaling } \\
\text { Technology }\end{array}$ \\
\hline Adam 10 & 14194 & 1:1000 & $\begin{array}{l}5 \% \text { BSA } \\
\text { in TBST }\end{array}$ & $\begin{array}{l}\text { Cell Signaling } \\
\text { Technology }\end{array}$ \\
\hline Flag & F7425 & $1: 1000$ & $\begin{array}{l}5 \% \text { Milk } \\
\text { in TBST }\end{array}$ & Merck \\
\hline
\end{tabular}

\section{Biochemical procedures}

Lysis. Cells were lysed by direct addition of 2x SDS-sample buffer (100 mM Tris- $\mathrm{HCl}, \mathrm{pH} 6.8,5 \mathrm{mM}$ EDTA/Na, 4\% SDS, 10\% glycerol, 0.4 M DTT, $0.02 \%$ bromophenol blue). Slices were collected in PBS and the pellet was lysed with RIPA buffer $(150 \mathrm{mM} \mathrm{NaCl}, 50 \mathrm{mM}$ Tris-Cl (pH 8), 1\% Tx-100, 0.5\% Na-deoxycholate and $0.1 \%$ SDS, protease and phosphatase inhibitor).

Tissue homogenization. Brains from 2 months or 6 months mice were homogenized in RIPA buffer with 30 strokes of a glassTeflon homogenizer and centrifuged at $15,000 \times g, 4{ }^{\circ} \mathrm{C}$ for $15 \mathrm{~min}$. The protein content was analyzed by BCA (ThermoFisher Scientific).

\section{Organotypic slice culture}

Organotypic slice cultures were prepared as described previously $[7,8]$. Briefly, young (postnatal days 5-7) C57BL/6J mice were sacrificed by decapitation and brains were isolated. The cerebellum, olfactory bulbs, and mid-brain were removed and the two hemispheres separated and placed onto the cutting stage of the tissue chopper (Mcllwain, model TC752, Mickle Laboratory Engineering Company). 350- $\mathrm{mm}$-thick sagittal sections were cut and further dissected. Intact cortico-hippocampal slices were selected under a dissection microscope (SZ61, Olympus) and incubated for $30 \mathrm{~min}$ at $4{ }^{\circ} \mathrm{C}$ in pre-cooled dissection media $(50 \%$ HEPES-buffered MEM, $1 \%$ penicillin-streptomycin, $10 \mathrm{mM}$ Tris, $\mathrm{pH}$ 7.2). Four slices were then plated onto each $0.4-\mu \mathrm{m}$ porous polytetrafluoroethylene (PTFE) membrane insert (PICMORG50, Millipore), placed in a $3.5-\mathrm{cm}$ dish with $1 \mathrm{ml}$ of slice culture media containing 50\% HEPES-buffered MEM, 25\% HBSS, $1 \mathrm{mM}$ L-glutamine (Gibco), and $25 \%$ heat-inactivated horse serum (Merck-Sigma) at pH 7.4 and maintained in a cell culture incubator at $37^{\circ} \mathrm{C}, 5 \% \mathrm{CO}_{2}$. Media was exchanged 1 day after preparation and subsequently every 3 days. Drugs were applied directly to the slice culture media and reapplied at every media exchange for a total of 7 days of treatment. Slices were treated with $25 \mu \mathrm{M}$ TBB alone or in combination with $10 \mu \mathrm{M}$ D4476 dissolved in DMSO or DMSO alone for the controls.

Viability of organotypic slices was assessed via propidium iodide staining and determination of LDH release in the culture medium (CytoTox 96 Non-Radioactive Cytotoxicity Assay, Promega, Madison, Wisconsin, USA).

\section{Immunohistochemistry}

Six-months-old transgenic mice from the APPPS1 and App ${ }^{N L-G-F}$ lines were anesthetized i.p. with a mixture of ketamine $(400 \mathrm{mg} /$ $\mathrm{kg})$ and Xylazine $(27 \mathrm{mg} / \mathrm{kg})$ and transcardially perfused with cold $0.1 \mathrm{M}$ PBS for $5 \mathrm{~min}$ followed by $4 \%$ Paraformaldehyde (PFA) in $0.1 \mathrm{M}$ PBS for $15 \mathrm{~min}$. Brains were then isolated and postfixed in $4 \%$ PFA-PBS for $20 \mathrm{~min}$ and transferred to $30 \%$ sucrose in $0.1 \mathrm{M}$ PBS for cryopreservation at $4{ }^{\circ} \mathrm{C}$. Once the brains sank in the sucrose solution, they were embedded in optimal cutting temperature compound (O.C.T./Tissue-Tek, Sakura), frozen on dry ice, and then kept at $-80^{\circ} \mathrm{C}$ until sectioning. $30 \mu \mathrm{m}$ coronal brain sections were cut using a cryostat (CryoSTAR NX70, ThermoScientific) and placed in $0.1 \mathrm{M}$ PBS until staining. Alternatively, sections were kept in anti-freezing solution (30\% Glycerol, $30 \%$ Ethylenglycol, $10 \% 0.25 \mathrm{M} \mathrm{PO}_{4}$ buffer, pH 7.2-7.4 and $30 \% \mathrm{dH}_{2} \mathrm{O}$ ) at $-20^{\circ} \mathrm{C}$ and briefly washed in $0.1 \mathrm{M}$ PBS before staining. Staining was performed in free-floating conditions [11]. Briefly, sections were permeabilized with $0.5 \%$ Triton-PBS (PBS-T) for $30 \mathrm{~min}$, then blocked in 5\% normal Goat Serum in PBS-T for $1 \mathrm{~h}$ and incubated overnight at $4{ }^{\circ} \mathrm{C}$ in blocking solution with the corresponding primary antibodies (rabbit anti-mouse elF4B, 1:100, Cell Signaling Technology; mouse anti-human A $\beta-N A B 228,1: 500$, Santa Cruz; rabbit anti-mouse BACE1, 1:250, Epitomics). After primary antibody incubation, sections were washed three times with PBS-T and incubated with corresponding secondary antibodies (1:500, 555 -conjugated goat anti-rabbit and 488-conjugated goat antimouse) together with DAPI (1:20:000) to visualize nuclei. Since costaining with elF4B and BACE1 antibodies was not possible due to the same species of origin, anti-elF4B/anti-A $\beta-N A B 228$ and antiBACE1/anti-A $\beta-N A B 228$ stainings were performed in parallel in contiguous brain sections from the same animals and corroborated in three mice from both mouse models. included as negative controls. Representative $\times 20$ and higher magnification $(\times 63)$ images were taken using confocal microscopy (z-stack, $\times 20$ dry objective and $\times 63$ water objective, respectively, Leica TCS SP5 II) from similar cortical regions. Z-stack images were converted to maximum intensity projections using the ImageJ software (NIH) for better visualization. 
Immunohistochemistry on human formalin-fixed, paraffinembedded sections was performed using a VENTANA OptiView DAB IHC Detection kit and acquired on a Benchmark Ultra system (Roche Diagnostics, Basel, Switzerland), according to the manufacturer instructions. Consecutive slices were stained with antibodies against human elF4B, anti-phospho Ser504 elF4B (Abcam, Cambridge, UK), and anti Amyloid beta (Agilent, Santa Clara, CA, USA). All tissue sections were stained and processed automatically, with the same protocol and in parallel. The concentration of the antibodies and the exposure time were determined as the best possible compromise to reveal elF4B, phospho Ser504 elF4B, and amyloid beta contemporaneously in healthy and $A D$ brain sections.

\section{MEA recordings}

Dissociated hippocampal cells were plated on poly-ornithine $(400 \mu \mathrm{g} / \mathrm{ml})$-treated multielectrode arrays (MEAs; Multi Channel Systems, Reutlingen, Germany) and maintained in the culture medium, previously described, for 10-11 DIV before recordings.

The electrical activity was analyzed at $37^{\circ} \mathrm{C}$ using the MEA1060inv-BC system (Multi Channel Systems MCS, Reutlingen, Germany). Data, recorded at $25 \mathrm{kHz} / \mathrm{ch}$ from 60 channels (corresponding to 60 electrodes present in the chip), were filtered from $300 \mathrm{~Hz}$ to $3 \mathrm{kHz}$. The firing rate was analyzed in the active channels (where at least 10 spikes $/ 5$ min occurred) and spikes were sorted using a threshold algorithm; this threshold corresponds to multiple of standard deviation of the biological noise during the first $500 \mathrm{~ms}$ of the recordings (spike $=5 \times$ S.D. noise). The firing rate was evaluated as the number of spikes recorded in a 20 min time window after the administration of $10 \mu \mathrm{M}$ bicuculline, compared with the number recorded in a 20 min time window before bicuculline treatment.

\section{Amyloid- $\beta$ detection}

Total $A \beta$ secreted in the culture media was evaluated by the ratmouse/human $A \beta$ high specific assay kit (Immuno-Biological Laboratories, Tokyo, Japan) according to the manufacturer's instructions.

\section{Statistical analysis}

Statistical analysis was performed with Prism software version 9.0 (GraphPad Software Inc., La Jolla, CA, USA). Columns in the graphs represent the mean $( \pm$ SEM). The number of experiments and the $p$ value are indicated in the figure legends, biological replicates are shown in graphs as individual points. The normality test (D'Agostino-Pearson) and equal variance test (Brown-Forsythe) were applied. In case of normally distributed data, statistical significance was evaluated (with $95 \%$ confidence intervals) by one-way ANOVA followed by Dunnett post hoc test (for multiple comparisons against a single reference group), Newman-Keuls or Tukey's post hoc test (for multiple comparisons between groups), two-tailed Student $t$-test (for comparisons between two average values); for samples with non-normal distributions, the nonparametric Mann-Whitney $U$ test (for significant differences between two experimental groups) and the Kruskal-Wallis one-way analysis of variance followed by Dunn's post hoc test (for the analysis of multiple experimental groups) were used. A value of $P<0.05$ was considered to be statistically significant. Sample size was calculated using G Power software (version 3.1), based on effect sizes calculated from our preliminary experiments, with a power of 0.8 and alpha $=0.05$.

\section{DATA AVAILABILITY}

All data generated or analysed during this study are included in this published article and its supplementary information files.

\section{REFERENCES}

1. Selkoe DJ, Hardy J. The amyloid hypothesis of Alzheimer's disease at 25 years. EMBO Mol Med. 2016;8:595-608.

2. Shankar GM, Li S, Mehta TH, Garcia-Munoz A, Shepardson NE, Smith I, et al. Amyloid- $\beta$ protein dimers isolated directly from Alzheimer's brains impair synaptic plasticity and memory. Nat. Med. 2008;14:837-42.

3. Gouras GK, Tampellini D, Takahashi RH, Capetillo-Zarate E. Intraneuronal $\beta$-amyloid accumulation and synapse pathology in Alzheimer's disease. Acta Neuropathol. 2010;119:523-41.

4. Ittner LM, Götz J. Amyloid- $\beta$ and tau-a toxic pas de deux in Alzheimer's disease. Nat Rev Neurosci. 2011;12:65-72.

5. Wyss-Coray T, Rogers J. Inflammation in Alzheimer disease-a brief review of the basic science and clinical literature. Cold Spring Harb Perspect Med. 2012;2: a006346.

6. Benilova I, Karran E, De Strooper B. The toxic A $\beta$ oligomer and Alzheimer's disease: an emperor in need of clothes. Nat. Neurosci. 2012;15:349-57.

7. De Strooper B, Vassar R, Golde T. The secretases: enzymes with therapeutic potential in Alzheimer disease. Nat Rev Neurol. 2010;6:99-107.

8. Karran E, Mercken M, De Strooper B. The amyloid cascade hypothesis for Alzheimer's disease: An appraisal for the development of therapeutics. Nat Rev Drug Discov. 2011;10:698-712.

9. Sevigny J, Chiao $P$, Bussière $T$, Weinreb $P H$, Williams L, Maier $M$, et al. The antibody aducanumab reduces $A \beta$ plaques in Alzheimer's disease. Nature. 2016;537:50-6.

10. Vassar R, Kovacs DM, Yan R, Wong PC. The beta-secretase enzyme BACE in health and Alzheimer's disease: regulation, cell biology, function, and therapeutic potential. J Neurosci. 2009;29:12787-94.

11. Yan R, Vassar R. Targeting the $\beta$ secretase BACE1 for Alzheimer's disease therapy. Lancet Neurol. 2014;13:319-29.

12. Ohno M. Alzheimer's therapy targeting the $\beta$-secretase enzyme BACE1: benefits and potential limitations from the perspective of animal model studies. Brain Res Bull. 2016;126:183-98.

13. Vassar R, Kuhn PH, Haass C, Kennedy ME, Rajendran L, Wong PC, et al. Function, therapeutic potential and cell biology of BACE proteases: current status and future prospects. J Neurochem. 2014;130:4-28.

14. Munro KM, Nash A, Pigoni M, Lichtenthaler SF, Gunnersen JM. Functions of the Alzheimer's disease protease BACE1 at the synapse in the central nervous system. J Mol Neurosci. 2016;60:305-15.

15. Barão S, Moechars D, Lichtenthaler SF, De Strooper B. BACE1 physiological functions may limit its use as therapeutic target for Alzheimer's disease. Trends Neurosci. 2016;39:158-69.

16. Rice HC, de Malmazet D, Schreurs A, Frere S, Van Molle I, Volkov AN, et al. Secreted amyloid- $\beta$ precursor protein functions as a $G A B A_{B}$ R1a ligand to modulate synaptic transmission. Science. 2019;363:eaao4827.

17. Richter MC, Ludewig S, Winschel A, Abel T, Bold C, Salzburger LR, et al. Distinct in vivo roles of secreted APP ectodomain variants APP sa and APP s $\beta$ in regulation of spine density, synaptic plasticity, and cognition. EMBO J. 37, e98335 (2018).

18. Egan MF, Kost J, Tariot PN, Aisen PS, Cummings JL, Vellas B, et al. Randomized trial of verubecestat for mild-to-moderate Alzheimer's disease. N Engl J Med. 2018;378:1691-703.

19. Egan MF, Kost J, Voss T, Mukai Y, Aisen PS, Cummings JL, et al. Randomized trial of verubecestat for prodromal Alzheimer's disease. $N$ Engl J Med. 2019;380:1408-20.

20. Novak G, Streffer JR, Timmers M, Henley D, Brashear HR, Bogert J, et al. Long-term safety and tolerability of atabecestat (JNJ-54861911), an oral BACE1 inhibitor, in early Alzheimer's disease spectrum patients: a randomized, double-blind, placebo-controlled study and a two-period extension study. Alzheimers Res Ther. 2020;12:58.

21. Zhao J, Fu Y, Yasvoina M, Shao P, Hitt B, O'Connor T, et al. Beta-site amyloid precursor protein cleaving enzyme 1 levels become elevated in neurons around amyloid plaques: implications for Alzheimer's disease pathogenesis. J Neurosci. 2007;27:3639-49.

22. Kandalepas PC, Sadleir KR, Eimer WA, Zhao J, Nicholson DA, Vassar R. The Alzheimer's $\beta$-secretase BACE1 localizes to normal presynaptic terminals and to dystrophic presynaptic terminals surrounding amyloid plaques. Acta Neuropathol. 2013;126:329-52.

23. Fukumoto $H$, Rosene $D L$, Moss MB, Raju S, Hyman BT, Irizarry MC. $\beta$-secretase activity increases with aging in human, monkey, and mouse. Brain Am J Pathol. 2004;164:719-25.

24. Busche MA, Eichhoff G, Adelsberger H, Abramowski D, Wiederhold K, Haass C, et al. Clusters of hyperactive neurons near amyloid plaques in a mouse model of Alzheimer's disease. Science. 2008;321:1686-9.

25. Busche MA, Chen X, Henning HA, Reichwald J, Staufenbiel M, Sakmann B, et al. Critical role of soluble amyloid-for early hippocampal hyperactivity in a mouse model of Alzheimer's disease. Proc Natl Acad Sci USA. 2012;109:8740-5. 
26. Ovsepian SV, O'Leary VB. Neuronal activity and amyloid plaque pathology: an update. J Alzheimers Dis. 2015;49:13-19.

27. Roßner S, Sastre M, Bourne K, Lichtenthaler SF. Transcriptional and translational regulation of BACE1 expression-Implications for Alzheimer's disease. Prog Neurobiol. 2006;79:95-111.

28. Tesco G, Koh YH, Kang EL, Cameron AN, Das S, Sena-Esteves M, et al. Depletion of GGA3 stabilizes BACE and enhances $\beta$-secretase activity. Neuron. 2007;54:721-37.

29. Zacchetti D, Chieregatti E, Bettegazzi B, Mihailovich M, Sousa VL, Grohovaz F, et al. BACE1 expression and activity: relevance in Alzheimer's disease. Neurodegener Dis. 2007;4:117-26.

30. Mihailovich M, Thermann R, Grohovaz F, Hentze MW, Zacchetti D. Complex translational regulation of BACE1 involves upstream AUGs and stimulatory elements within the $5^{\prime}$ untranslated region. Nucleic Acids Res. 2007;35:2975-85.

31. Bettegazzi B, Mihailovich M, Di Cesare A, Consonni A, Macco R, Pelizzoni I, et al. $\beta$-Secretase activity in rat astrocytes: translational block of BACE1 and modulation of BACE2 expression. Eur J Neurosci. 2011;33:236-43.

32. Hebert SS, Horre K, Nicolai L, Papadopoulou AS, Mandemakers W, Silahtaroglu AN, et al. Loss of microRNA cluster miR-29a/b-1 in sporadic Alzheimer's disease correlates with increased BACE1/ beta-secretase expression. Proc Natl Acad Sci USA. 2008;105:6415-20.

33. Wang W-X, Rajeev BW, Stromberg AJ, Ren N, Tang G, Huang Q, et al. The expression of microRNA miR-107 decreases early in Alzheimer's disease and may accelerate disease progression through regulation of beta-site amyloid precursor protein-cleaving enzyme 1. J Neurosci. 2008;28:1213-23.

34. Boissonneault V, Plante I, Rivest S, Provost P. MicroRNA-298 and microRNA-328 regulate expression of mouse $\beta$-amyloid precursor protein-converting enzyme 1 . J Biol Chem. 2009;284:1971-81.

35. O'Connor T, Sadleir KR, Maus E, Velliquette RA, Zhao J, Cole SL, et al. Phosphorylation of the translation initiation factor elF2a increases BACE1 levels and promotes amyloidogenesis. Neuron. 2008;60:988-1009.

36. Sadleir KR, Eimer WA, Kaufman RJ, Osten P, Vassar R. Genetic inhibition of phosphorylation of the translation initiation factor elF2a does not block a $\beta$-dependent elevation of BACE1 and APP levels or reduce amyloid pathology in a mouse model of Alzheimer's disease. PLoS ONE. 2014;9:e101643.

37. Lee $\mathrm{HJ}$, Ryu JM, Jung YH, Lee SJ, Kim JY, Lee $\mathrm{SH}$, et al. High glucose upregulates BACE1-mediated $A \beta$ production through ROS-dependent HIF-1a and LXRa/ ABCA1-regulated lipid raft reorganization in SK-N-MC cells. Sci Rep. 2016;6:1-15.

38. Shahbazian D, Parsyan A, Petroulakis E, Hershey J, Sonenberg N. elF4B controls survival and proliferation and is regulated by proto-oncogenic signaling pathways. Cell Cycle. 2010;9:4106-9.

39. Shahbazian D, Parsyan A, Petroulakis E, Topisirovic I, Martineau Y, Gibbs BF, et al. Control of cell survival and proliferation by mammalian eukaryotic initiation factor 4B. Mol Cell Biol. 2010;30:1478-85.

40. Eom T, Muslimov IA, Tsokas $P$, Berardi V, Zhong J, Sacktor TC, et al. Neuronal BC RNAs cooperate with elF4B to mediate activity-dependent translational control. J Cell Biol. 2014:207:237-52.

41. Bettegazzi B, Bellani S, Roncon P, Guarnieri FC, Bertero A, Codazzi F, et al. EIF4B phosphorylation at Ser504 links synaptic activity with protein translation in physiology and pathology. Sci Rep. 2017;7:1-16.

42. Lammich S, Schöbel S, Zimmer AK, Lichtenthaler SF, Haass C. Expression of the Alzheimer protease BACE1 is suppressed via its $5^{\prime}$-untranslated region. EMBO Rep. 2004;5:620-5.

43. De Pietri Tonelli D, Mihailovich M, Di Cesare A, Codazzi F, Grohovaz F, Zacchetti D. Translational regulation of BACE-1 expression in neuronal and non-neuronal cells. Nucleic Acids Res. 2004;32:1808-17.

44. Nielsen KH, Behrens MA, He Y, Oliveira CLP, Sottrup Jensen L, Hoffmann SV, et al. Synergistic activation of elF4A by elF4B and elF4G. Nucleic Acids Res. 2011;39:2678-89.

45. Harms U, Andreou AZ, Gubaev A, Klostermeier D. EIF4B, elF4G and RNA regulate elF4A activity in translation initiation by modulating the elF4A conformational cycle. Nucleic Acids Res. 2014;42:7911-22.

46. Kuhn PH, Koroniak K, Hogl S, Colombo A, Zeitschel U, Willem M, et al. Secretome protein enrichment identifies physiological BACE1 protease substrates in neurons. EMBO J. 2012;31:3157-68.

47. Zhu K, Peters F, Filser S, Herms J. Consequences of pharmacological BACE inhibition on synaptic structure and function. Biol Psychiatry. 2018;84:478-87.

48. Das B, Yan R. Role of BACE1 in Alzheimer's synaptic function. Transl Neurodegener. 2017:6:4-11.

49. Styr B, Slutsky I. Imbalance between firing homeostasis and synaptic plasticity drives early-phase Alzheimer's disease. Nat Neurosci. 2018;21:463-73.

50. Ruzzene M, Bertacchini J, Toker A, Marmiroli S. Cross-talk between the CK2 and AKT signaling pathways in cancer. Adv Biol Regul. 2017;64:1-8.

51. Sadleir KR, Kandalepas PC, Buggia-Prévot V, Nicholson DA, Thinakaran G, Vassar R. Presynaptic dystrophic neurites surrounding amyloid plaques are sites of microtubule disruption, BACE1 elevation, and increased $A \beta$ generation in Alzheimer's disease. Acta Neuropathol. 2016;132:235-56.

52. Ren S, Chen P, Jiang $H, M i ~ Z, X u ~ F, ~ H u ~ B$, et al. Persistent sodium currents contribute to $A \beta 1-42$-induced hyperexcitation of hippocampal CA1 pyramidal neurons. Neurosci Lett. 2014;580:62-67.

53. Tamagnini F, Scullion S, Brown JT, Randall AD. Intrinsic excitability changes induced by acute treatment of hippocampal CA1 pyramidal neurons with exogenous amyloid $\beta$ peptide: A $\beta$ ALTERS INTRINSIC NEURONAL PROPERTIES. Hippocampus. 2015;25:786-97.

54. Sadleir KR, Vassar R. Cdk5 protein inhibition and A 342 increase BACE1 protein level in primary neurons by a post-transcriptional mechanism: Implications of CDK5 as a therapeutic target for Alzheimer disease. J Biol Chem. 2012;287:7224-35.

55. Mamada N, Tanokashira D, Hosaka A, Kametani F, Tamaoka A, Araki W. Amyloid $\beta$-protein oligomers upregulate the $\beta$-secretase, BACE1, through a posttranslational mechanism involving its altered subcellular distribution in neurons. Mol Brain. 2015;8:1-12.

56. Radde R, Bolmont T, Kaeser SA, Coomaraswamy J, Lindau D, Stoltze L, et al. A $\beta 42$ driven cerebral amyloidosis in transgenic mice reveals early and robust pathology. EMBO Rep. 2006;7:940-6.

57. Saito T, Matsuba Y, Mihira N, Takano J, Nilsson P, Itohara S, et al. Single App knock-in mouse models of Alzheimer's disease. Nat Neurosci. 2014;17:661-3.

58. Croft CL, Wade MA, Kurbatskaya K, Mastrandreas $P$, Hughes MM, Phillips EC, et al Membrane association and release of wild-type and pathological tau from organotypic brain slice cultures. Cell Death Dis. https://doi.org/10.1038/ cddis.2017.97 (2017)

59. Biber K. Reestablishing microglia function: good news for Alzheimer's therapy? EMBO J. 2017;36:565-7.

60. Daria A, Colombo A, Llovera G, Hampel H, Willem M, Liesz A, et al. Young microglia restore amyloid plaque clearance of aged microglia. EMBO J. 2017;36:583-603.

61. Novotny R, Langer F, Mahler J, Skodras A, Vlachos A, Wegenast-Braun BM, et al Conversion of synthetic $A \beta$ to in vivo active seeds and amyloid plaque formation in a hippocampal slice culture model. J Neurosci. 2016;36:5084-93.

62. Sun X, Bromley-Brits K, Song W. Regulation of $\beta$-site APP-cleaving enzyme 1 gene expression and its role in Alzheimer's disease. J Neurochem. 2012;120:62-70.

63. Sen ND, Zhou F, Harris MS, Ingolia NT, Hinnebusch AG. elF4B stimulates translation of long mRNAs with structured $5^{\prime}$ UTRs and low closed-loop potential but weak dependence on elF4G. Proc Natl Acad Sci USA. 2016;113:10464-72.

64. Holz MK, Ballif BA, Gygi SP, Blenis J. mTOR and S6K1 mediate assembly of the translation preinitiation complex through dynamic protein interchange and ordered phosphorylation events. Cell. 2005;123:569-80.

65. Dennis MD, Jefferson LS, Kimball SR. Role of p70S6K1-mediated phosphorylation of elF4B and PDCD4 proteins in the regulation of protein synthesis. J Biol Chem. 2012;287:42890-9.

66. Cajigas IJ, Tushev G, Will TJ, Tom Dieck S, Fuerst N, Schuman EM. The local transcriptome in the synaptic neuropil revealed by deep sequencing and highresolution imaging. Neuron. 2012;74:453-66.

67. Zappulo A, Van Den Bruck D, Ciolli Mattioli C, Franke V, Imami K, McShane E, et al. RNA localization is a key determinant of neurite-enriched proteome. Nat Commun. 2017;8:583.

68. Bero AW, Yan P, Roh JH, Cirrito JR, Stewart FR, Raichle ME, et al. Neuronal activity regulates the regional vulnerability to amyloid- $\beta$ deposition. Nat Neurosci. 2011;14:750-6.

69. Cirrito JR, Kang J-E, Lee J, Stewart FR, Verges DK, Silverio LM, et al. Endocytosis is required for synaptic activity-dependent release of amyloid- $\beta$ in vivo. Neuron. 2008;58:42-51.

70. Kamenetz F, Tomita T, Hsieh H, Seabrook G, Borchelt D, Iwatsubo T, et al. APP processing and synaptic function. Neuron. 2003;37:925-37.

71. Das U, Scott DA, Ganguly A, Koo EH, Tang Y, Roy S. Activity-induced convergence of APP and BACE-1 in acidic microdomains via an endocytosis-dependent pathway. Neuron. 2013;79:447-60.

72. Sperling RA, LaViolette PS, O'Keefe K, O'Brien J, Rentz DM, Pihlajamaki M. et al. deposition is associated with impaired default network function in older persons without dementia. Neuron. 2009;63:178-88.

73. Palop JJ, Mucke L. Network abnormalities and interneuron dysfunction in Alz heimer disease. Nat Rev Neurosci. 2016;17:777-92.

74. Lam AD, Deck G, Goldman A, Eskandar EN, Noebels J, Cole AJ. Silent hippocampal seizures and spikes identified by foramen ovale electrodes in Alzheimer's disease. Nat Med. 2017:23:678-80.

75. Baleriola J, Walker CA, Jean YY, Crary JF, Troy CM, Nagy PL, et al. Axonally synthesized ATF4 transmits a neurodegenerative signal across brain regions. Cell. 2014;158:1159-72. 
14

76. Cefaliello C, Penna E, Barbato C, Di Ruberto G, Mollica MP, Trinchese G, et al. Deregulated local protein synthesis in the brain synaptosomes of a mouse model for Alzheimer's disease. Mol Neurobiol. 2020;57:1529-41.

77. Zhu BL, Long Y, Luo W, Yan Z, Lai YJ, Zhao LG, et al. MMP13 inhibition rescues cognitive decline in Alzheimer transgenic mice via BACE1 regulation. Brain. 2019;142:176-92.

78. Lomoio S, Willen R, Kim W, Ho KZ, Robinson EK, Prokopenko D, et al. Gga3 deletion and a GGA3 rare variant associated with late onset Alzheimer's disease trigger BACE1 accumulation in axonal swellings. Sci Transl Med. 2020;12:eaba1871.

79. Ye X, Feng T, Tammineni $P$, Chang Q, Jeong YY, Margolis DJ, et al. Regulation of synaptic amyloid- $\beta$ generation through BACE1 retrograde transport in a mouse model of Alzheimer's disease. J Neurosci. 2017;37:2639-55.

80. Stokin GB. Axonopathy and transport deficits early in the pathogenesis of Alzheimer's disease. Science. 2005;307:1282-8.

\section{ACKNOWLEDGEMENTS}

We thank Mathias Jucker for sharing the APPPS1 mice and Stephan Lichtenthaler for sharing 5G11 and BAWT antibodies. Part of this work was carried out in ALEMBIC, the advanced microscopy laboratory established by the San Raffaele Scientific Institute and University.

\section{AUTHOR CONTRIBUTIONS}

BB designed and performed experiments and wrote the manuscript. DZ obtained funding, designed and supervised experiments, and revised the manuscript. LSM performed experiments and revised the manuscript. ST and FG supervised experiments and revised the manuscript. TS and TCS provided essential reagents. LMR, ND, and SF performed experiments on human tissue sections. SB, FC, AVC, and $S L$ discussed experiments and participated in manuscript writing. All authors read and approved the final manuscript.

\section{FUNDING}

This work was carried out within the framework of the NeOn project (ID 239047 to DZ), with the financial support of Regione Lombardia (POR FESR 2014-2020), and the Ivascomar project (CTN01_00177_165430 to DZ), Cluster Tecnologico Nazionale Scienze della Vita "Alisei", Italian Ministry of Research. Barbara Bettegazzi was a PhD student of the International PhD School in Molecular Medicine, San Raffaele University and received a short-term EMBO fellowship. Funds have been provided to S.T. by the Alzheimer Forschung Initiative e.V. (Grant number 18014).

\section{COMPETING INTERESTS}

The authors declare no competing interests.

\section{ETHICS STATEMENT}

All animal studies were approved by the Institutional Animal Care and Use Committee of San Raffaele Scientific Institute and by the government of Upper Bavaria. Human tissue samples were obtained from the Biobank of the Institute of Medical Genetics and Pathology, Basel University Hospital, Basel, Switzerland. Human tissue sample study was approved by the San Raffaele Scientific Institute.

\section{ADDITIONAL INFORMATION}

Supplementary information The online version contains supplementary material available at https://doi.org/10.1038/s41419-021-04062-3.

Correspondence and requests for materials should be addressed to B.B. or D.Z.

Reprints and permission information is available at http://www.nature.com/ reprints

Publisher's note Springer Nature remains neutral with regard to jurisdictional claims in published maps and institutional affiliations.

(i) Open Access This article is licensed under a Creative Commons Attribution 4.0 International License, which permits use, sharing, adaptation, distribution and reproduction in any medium or format, as long as you give appropriate credit to the original author(s) and the source, provide a link to the Creative Commons license, and indicate if changes were made. The images or other third party material in this article are included in the article's Creative Commons license, unless indicated otherwise in a credit line to the material. If material is not included in the article's Creative Commons license and your intended use is not permitted by statutory regulation or exceeds the permitted use, you will need to obtain permission directly from the copyright holder. To view a copy of this license, visit http://creativecommons. org/licenses/by/4.0/.

(c) The Author(s) 2021 